\title{
Chapter 7 \\ Case Studies of Math Education for STEM in Russia
}

\subsection{Analysis of Mathematical Courses in KNRTU-KAI}

Ildar Galeev $(\bowtie)$ and Svetlana Novikova and Svetlana Medvedeva

Kazan National Research Technical University named after A.N. Tupolev-KAI (KNRTU-KAI), Automated Systems of Information Processing and Control Department, Kazan, Russia

e-mail: monap@kstu.ru; sweta72@bk.ru; pmisvet@yandex.ru

\subsubsection{Kazan National Research Technical University named after A.N. Tupolev-KAI (KNRTU-KAI)}

Kazan National Research Technical University named after A.N. Tupolev-KAI (KNRTU-KAI) was established in 1932. The history of the University is closely related to the progress of Russian aeronautics. Fundamental education and profound scientific research are the distinguishing features of the university, which make it very attractive for a great number of young people. Until recent times, it was known as Kazan Aviation Institute (KAI).

In 1973, the Institute was named after Andrey N. Tupolev, the prominent aircraft designer. In 1992, it obtained the status of State Technical University. In 2009, KNRTU-KAI became 1 of 12 universities selected among all the Russian universities (from about 900 state HE institutions and 2000 private ones) which was awarded the prestigious title of the "National Research University".

KNRTU-KAI is a member of the European Universities Association EUA (2008) and of the European Association of Aerospace Universities PEGASUS (2009). 
KNRTU-KAI is the largest multidisciplinary educational and scientific complex of the Republic of Tatarstan and the Volga region. The structure KNRTU-KAI includes five institutes, one faculty, five branches in the Republic of Tatarstan (Almetyevsk, Zelenodolsk, Naberezhnye Chelny, Chistopol, Leninogorsk). Despite having the institute of Economics, Management and Social Technologies in its structure, KNRTU should be considered as a technical university. The other four of five main institutes and one faculty are completely devoted to engineering and computer science specializations.

Today KNRTU-KAI is one of the leading Russian institutions in aircraft engineering, engine- and instrument-production, computer science and radio- and telecommunications engineering.

The university includes the following institutes and faculties:

- Institute of Aviation, Land Vehicles \& Energetics

- Institute of Automation \& Electronic Instrument-Making

- Institute of Technical Cybernetics \& Informatics

- Institute of Radio-Engineering \& Telecommunications

- Institute of Economics, Management and Social Technologies

- Physics \& Mathematics Faculty

There is also the German-Russian Institute of Advanced Technologies (GRIAT). German Partners of this institute are Ilmenau Institute of Technology, TU Ilmenau, Otto-von-Guericke-Universität Magdeburg, OVGU, and Deutscher Akademischer Austauschdienst, DAAD.

Currently there are more than 12,000 students in the university. Most of them (more than 10,000) are technical (STEM) students. In total at six institutes and one faculty there are 29 Bachelor and 30 Master STEM programs (including 9 Master STEM programs of the Institute GRIAT), also there is six Specialist (specific Russian 5-year grade).

The mathematical training at the University is carried out by Department of Higher Mathematics, Department of Special Mathematics, and Department of Applied Mathematics and Computer Science.

Departments of Higher Mathematics (the total number of teachers is 8) and Special Mathematics (the total number of teachers is 18) carry out classical mathematical training in classical engineering programs.

The department of Applied Mathematics and Computer Science trains Bachelors and Masters in the following study programs:

- "Informatics and Computer Science" (B.Sc., MSc);

- "Mathematics and Computer Science" (B.Sc., MSc);

- "Software Engineering" (B.Sc., MSc).

It also provides specialized courses for other areas within the university and in the Institute of Computer Technology and Information Protection. The educational process is realized by the department under the innovation program "Industrial production of software and information technology tools" in accordance with state educational standards of the Russian Federation and international standards on 
Computing Curricula and on professional standards in the field of information technology. The staff of this department consists of 6 full-time professors, 12 fulltime associate professors, 2 full-time assistant professors, 2 teachers and 6 technical specialists.

There are most general courses in all areas of training; the Institute of Computer Technology and Information Protection provides courses in mathematics: algebra and geometry, calculus, discrete mathematics, probability theory and mathematical statistics, computational mathematics.

The Institute of Computer Technology and Information Protection has six chairs:

- Department of Applied Mathematics and Computer Science

- Department of Information Security Systems

- Department of Computer Aided Design

- Department of Automated Data Processing Systems and Management

- Department of Computer Systems

- Department of Process Dynamics and Control

In 2015, unified training Bachelor's plans were accepted at the university, in which a block of mathematical courses is the same for all STEM programs.

The block of mandatory mathematics for all STEM programs includes the following courses: Calculus, Algebra and Geometry, Probability Theory and Mathematical Statistics (semesters 1-4). The courses Discrete Mathematics and Mathematical Logic and Theory of Algorithms are included in the block of mandatory courses for the training of IT-professionals. The course of Computational Mathematics (semester 5) is in the block of selective courses for the training of IT-professionals. Other mathematical courses, such as Differential Equations, Mathematical Physics, Complex Analysis and Functional Analysis in the selective block, are courses for training of specialists by an in-depth study of mathematics. An example of this Bachelor program is the program of Mathematics and Computer Science.

\subsubsection{Comparative Analysis of "Probability Theory and Mathematical Statistics"}

"Probability Theory and Mathematical Statistics" is a theoretical course with approximately 3000 students. There are around 240 second year students, from 6 Bachelor and 2 Specialist of Institute of Computer Technology and Information Protection (ICTIP) programs, who study this course at the Department of Applied Mathematics and Computer Science. A comparison of this course was conducted with the corresponding courses "Probability Calculus" and "Statistics" by Tampere University of Technology (TUT). The course outlines are presented in Table 7.1. 
Table 7.1 Outlines of probability theory and statistics courses at KNRTU-KAI and TUT

\begin{tabular}{l|l|l}
\hline Course information & KNRTU-KAI & TUT \\
\hline Bachelor/master level & Bachelor & Bachelor \\
\hline Preferred year & 2 & 2 \\
\hline Selective/mandatory & Mandatory & Mandatory \\
\hline Number of credits & 6 & $4+4$ \\
\hline Teaching hours & 90 & 84 \\
\hline Preparatory hours & 108 & 132 \\
\hline Teaching assistants & 1 & $1-4$ \\
\hline Computer labs & Available & Available \\
\hline Average number of students on the course & 60 & 200 \\
\hline Average pass \% & $85 \%$ & $90 \%$ \\
\hline$\%$ of international students & None & None \\
\hline & &
\end{tabular}

"Probability Theory and Mathematical Statistics" is a mandatory Bachelor level course on second year-Probability Theory (third semester) and Mathematical Statistics (4th semester). Its prerequisite courses are: Calculus (first, second semesters), Algebra and Geometry (second semester), Discrete Mathematics (second, third semesters), and Mathematical Logics and Theory of Algorithms (third semester). Prerequisite courses at TUT are Engineering Mathematics 1-4. The follow-up courses are Theory of Stochastic Processes and System, Programming and various special courses of all six ICTIP Bachelor programs.

In 2011, KNRTU-KAI has started to use LMS Blackboard, which is a learning management system supporting e-learning. The content of educational materials is included in the LMS Blackboard in a form suitable for e-learning. For Probability Theory and Mathematical Statistics an e-learning course was developed for the LMS Blackboard environment. It contains the mandatory e-learning componentscourse schedule, lecture notes, guidelines for tutorials, computer labs, as well as independent student work. There is also a mandatory component - a test for students on theoretical items of the course. Thus, KNRTU-KAI uses a blended form of learning types that combines classroom instruction with students' independent work using the LMS Blackboard environment.

The size of the course is 6 credits, which means on average $216 \mathrm{~h}$ of student's work ( $36 \mathrm{~h}$ for each credit). The credits are divided among different activities as follows: lectures $36 \mathrm{~h}$, tutorials $54 \mathrm{~h}$, computer labs $18 \mathrm{~h}$, homework $72 \mathrm{~h}$ and $36 \mathrm{~h}$ for preparing to the examination.

There are about 240 students studying the course every year at the Institute of Computer Technology and Information Protection. About 10\% of them are foreign students and about $20 \%$ are female.

The lectures are theoretical, but application examples for every theorem and algorithm are shown as well. Tutorial classes are completely devoted to problem solving, generally using paper and pen, but also MATLAB and Excel are used in solving some problems. Computer labs use our own computer textbook "Introduc- 
tion to Mathematical Statistics" in real-time. This allows the students to generate a sample from a given distribution, to build and explore random functions and their density distributions, as well as to build and explore their numerical characteristics, and to carry out and explore the algorithms for testing statistical hypothesis and one-dimensional regression analysis.

Generally, our students have to pass four tests and complete four individual laboratory workshops during the two semesters. When all this work has successfully been done, they are allowed to take an exam. In the exam a student has to answer thoroughly two questions from random topics, and to briefly answer some additional questions. Prior to this, all the students of a group had to take a pen and paper test of 15 test items, which allows the teacher to determine the readiness of students for the exam. The final grade is determined by the examiner. The grade depends on how successfully all the parts of the exams were passed, and it takes into account the test results, students' practical work and laboratory work during the semester. The final grade is mathematically dependent on the number of points in accordance with the score-rating system, adopted by the university. The score-rating systems is the following:

- less than 50 points is unsatisfactory (grade “" 2 "),

- from 50 to 69 points is satisfactory (grade “3"),

- from 70 to 84 points is good (grade “4”),

- more than 84 points is excellent (grade " 5 ").

The course is supported by the following educational software and TEL tools:

- MATLAB and Excel are used in tutorials for solving some problems.

- The computer textbook "Introduction to Mathematical Statistics" is used for construction and study of statistical estimations of distributions and their parameters, and also for testing the knowledge and monitoring and evaluating the skills of students in mathematical statistics.

- The e-Learning Systems LMS Blackboard platform is used for testing the students' knowledge on our course.

Since September 2016, we have used the Math-Bridge system for training in and monitoring of students' abilities in solving problems in the theory of probability. The piloting operation of the Math-Bridge system has been done as a part of the MetaMath project.

\subsubsection{Contents of the Course}

The comparison is based on the SEFI framework [1]. Prerequisite competencies are presented in Table 7.2. Outcome competencies are given in Tables 7.3, 7.4, and 7.5. 
Table 7.2 Core 0 level prerequisite competencies of probability theory and statistics courses at KNRTU-KAI and TUT

\begin{tabular}{l|l|l}
\hline Core 0 & KNRTU-KAI & TUT \\
\hline Competency & With some exceptions ${ }^{\mathrm{a}}$ & $\mathrm{X}$ \\
\hline Data handling & With some exceptions $^{\mathrm{b}}$ & $\mathrm{X}$ \\
\hline Probability & $\mathrm{X}$ & $\mathrm{X}$ \\
\hline Arithmetic of real numbers & $\mathrm{X}$ & $\mathrm{X}$ \\
\hline Algebraic expressions and formulas & $\mathrm{X}$ & $\mathrm{X}$ \\
\hline Functions and their inverses & $\mathrm{X}$ & $\mathrm{X}$ \\
\hline Sequences, series, binomial expansions & $\mathrm{X}$ & $\mathrm{X}$ \\
\hline Logarithmic and exponential functions & $\mathrm{X}$ & $\mathrm{X}$ \\
\hline Indefinite integration & $\mathrm{X}$ & $\mathrm{X}$ \\
\hline Definite integration, applications to areas and volumes & $\mathrm{X}$ & $\mathrm{X}$ \\
\hline Proof & $\mathrm{X}$ & $\mathrm{X}$ \\
\hline Sets & & $\mathrm{X}$ \\
\hline
\end{tabular}

${ }^{a}$ Interpret data presented in the form of line diagrams, bar charts, pie charts; interpret data presented in the form of stem and leaf diagrams, box plots, histograms; construct line diagrams, bar charts, pie charts, stem and leaf diagrams, box plots, histograms for suitable data sets; calculate the mode, median and mean for a set of data items

befine the terms "outcome", "event" and "probability"; calculate the probability of an event by counting outcomes; calculate the probability of the complement of an event; calculate the probability of the union of two mutually exclusive events; calculate the probability of the union of two events; calculate the probability of the intersection of two independent events

Table 7.3 Core 0 level outcome competencies of probability theory and statistics courses at KNRTU-KAI and TUT

\begin{tabular}{l|l|l}
\hline Core 0 & KNRTU-KAI & TUT \\
\hline Competency & $\mathrm{X}$ & $\mathrm{X}$ \\
\hline Calculate the mode, median and mean for a set of data items & $\mathrm{X}$ & $\mathrm{X}$ \\
\hline Define the terms 'outcome', 'event' and 'probability' & $\mathrm{X}$ & $\mathrm{X}$ \\
\hline Calculate the probability of an event by counting outcomes & $\mathrm{X}$ & $\mathrm{X}$ \\
\hline Calculate the probability of the complement of an event & $\mathrm{X}$ & $\mathrm{X}$ \\
\hline Calculate the probability of the union of two mutually exclusive events & $\mathrm{X}$ & $\mathrm{X}$ \\
\hline Calculate the probability of the union of two events & $\mathrm{X}$ \\
\hline Calculate the probability of the intersection of two independent events & $\mathrm{X}$ &
\end{tabular}

\subsubsection{Summary of the Results}

The comparison shows that the two courses cover generally the same topics and competences. A difference was observed in the place of the course in the curriculum of the degree program. The course on Probability theory and mathematical statistics is studied in the third and fourth semesters in KNRTU-KAI, but at TUT this course is studied during the fourth and fifth semesters, depending on the given study program. Before MetaMath project there were more differences: in KNRTU-KAI this course was studied in the second semester (first year of training). No difference was observed in the total number of hours. 
Table 7.4 Core 1 level outcome competencies of the probability theory and statistics courses at KNRTU-KAI and TUT

\begin{tabular}{|c|c|c|}
\hline \multicolumn{3}{|l|}{ Core 1} \\
\hline Competency & KNRTU-KAI & TUT \\
\hline $\begin{array}{l}\text { Calculate the range, inter-quartile range, variance and standard } \\
\text { deviation for a set of data items }\end{array}$ & $\mathrm{X}$ & $\mathrm{X}$ \\
\hline Distinguish between a population and a sample & $\mathrm{X}$ & $\mathrm{X}$ \\
\hline $\begin{array}{l}\text { Know the difference between the characteristic values (moments) of a } \\
\text { population and of a sample }\end{array}$ & $\mathrm{X}$ & $\mathrm{X}$ \\
\hline Construct a suitable frequency distribution from a data set & $\mathrm{X}$ & $\mathrm{X}$ \\
\hline Calculate relative frequencies & $\mathrm{X}$ & $\mathrm{X}$ \\
\hline Calculate measures of average and dispersion for a grouped set of data & $\mathrm{X}$ & $\mathrm{X}$ \\
\hline Understand the effect of grouping on these measures & $\mathrm{X}$ & $\mathrm{X}$ \\
\hline Use the multiplication principle for combinations & $\mathrm{X}$ & $\mathrm{X}$ \\
\hline Interpret probability as a degree of belief & $\mathrm{X}$ & $\mathrm{X}$ \\
\hline $\begin{array}{l}\text { Understand the distinction between a priori and a posteriori } \\
\text { probabilities }\end{array}$ & $\mathrm{X}$ & $\mathrm{X}$ \\
\hline Use a tree diagram to calculate probabilities & $\mathrm{X}$ & $\mathrm{X}$ \\
\hline $\begin{array}{l}\text { Know what conditional probability is and be able to use it (Bayes' } \\
\text { theorem) }\end{array}$ & $\mathrm{X}$ & $\mathrm{X}$ \\
\hline Calculate probabilities for series and parallel connections & $\mathrm{X}$ & $\mathrm{X}$ \\
\hline Define a random variable and a discrete probability distribution & $X$ & $\mathrm{X}$ \\
\hline State the criteria for a binomial model and define its parameters & $\mathrm{X}$ & $\mathrm{X}$ \\
\hline Calculate probabilities for a binomial model & $\mathrm{X}$ & $\mathrm{X}$ \\
\hline State the criteria for a Poisson model and define its parameters & $\mathrm{X}$ & $\mathrm{X}$ \\
\hline Calculate probabilities for a Poisson model & $X$ & $X$ \\
\hline State the expected value and variance for each of these models & $\mathrm{X}$ & $\mathrm{X}$ \\
\hline Understand what a random variable is continuous & $\mathrm{X}$ & $\mathrm{X}$ \\
\hline $\begin{array}{l}\text { Explain the way in which probability calculations are carried out in the } \\
\text { continuous case }\end{array}$ & $\mathrm{X}$ & $\mathrm{X}$ \\
\hline $\begin{array}{l}\text { Relate the general normal distribution to the standardized normal } \\
\text { distribution }\end{array}$ & $\mathrm{X}$ & $\mathrm{X}$ \\
\hline Define a random sample & $\mathrm{X}$ & $\mathrm{X}$ \\
\hline Know what a sampling distribution is & $\mathrm{X}$ & $\mathrm{X}$ \\
\hline Understand the term 'mean squared error' of an estimate & $X$ & $X$ \\
\hline Understand the term 'unbiasedness' of an estimate & $X$ & $X$ \\
\hline
\end{tabular}

Thus, as a result of the modernization, the number of hours in the course "Probability theory and mathematical statistics" now fully coincide: in the third semester $108 \mathrm{~h}$ ( 3 credit units in the second year) and "Mathematical Statistics" $108 \mathrm{~h}$ in the fourth semester ( 3 credit units in the third year). Studying the course has been shifted from the first to the second year.

A comparison on the use of information technology in the course "Probability Theory and Mathematical Statistics" was carried out in the two universities. The use of information technology in teaching this course is on a high level. 
Table 7.5 Core 2 level outcome competencies of the probability theory and statistics courses at KNRTU-KAI and TUT

\begin{tabular}{|c|c|c|}
\hline \multicolumn{3}{|l|}{ Core 2} \\
\hline Competency & KNRTU-KAI & TUT \\
\hline Compare empirical and theoretical distributions & $\mathrm{X}$ & $\mathrm{X}$ \\
\hline Apply the exponential distribution to simple problems & $\mathrm{X}$ & $\mathrm{X}$ \\
\hline Apply the normal distribution to simple problems & $\mathrm{X}$ & $\mathrm{X}$ \\
\hline Apply the gamma distribution to simple problems & $\mathrm{X}$ & $X$ \\
\hline Understand the concept of a joint distribution & $\mathrm{X}$ & $\mathrm{X}$ \\
\hline $\begin{array}{l}\text { Understand the terms 'joint density function', 'marginal distribution } \\
\text { functions' }\end{array}$ & $\mathrm{X}$ & $\mathrm{X}$ \\
\hline Define independence of two random variables & $\mathrm{X}$ & $\mathrm{X}$ \\
\hline Solve problems involving linear combinations of random variables & $\mathrm{X}$ & $X$ \\
\hline Determine the covariance of two random variables & $\mathrm{X}$ & $\mathrm{X}$ \\
\hline Determine the correlation of two random variables & $\mathrm{X}$ & $\mathrm{X}$ \\
\hline $\begin{array}{l}\text { Realize that the normal distribution is not reliable when used with } \\
\text { small samples }\end{array}$ & $X$ & $X$ \\
\hline Use tables of the $t$-distribution & $\mathrm{X}$ & $\mathrm{X}$ \\
\hline Use tables of the $F$-distribution & $\mathrm{X}$ & $\mathrm{X}$ \\
\hline Use the method of pairing where appropriate & $\mathrm{X}$ & $X$ \\
\hline Use tables for chi-squared distributions & $\mathrm{X}$ & $X$ \\
\hline $\begin{array}{l}\text { Decide on the number of degrees of freedom appropriate to a particular } \\
\text { problem }\end{array}$ & $\mathrm{X}$ & $X$ \\
\hline $\begin{array}{l}\text { Use the chi-square distribution in tests of independence (contingency } \\
\text { tables) }\end{array}$ & $\mathrm{X}$ & $\mathrm{X}$ \\
\hline Use the chi-square distribution in tests of goodness of fit & $\mathrm{X}$ & $\mathrm{X}$ \\
\hline Set up the information for a one-way analysis of variance & $\mathrm{X}$ & $\mathrm{X}$ \\
\hline Derive the equation of the line of best fit to a set of data pairs & $\mathrm{X}$ & $\mathrm{X}$ \\
\hline Calculate the correlation coefficient & $\mathrm{X}$ & $X$ \\
\hline Place confidence intervals around the estimates of slope and intercept & $\mathrm{X}$ & $X$ \\
\hline $\begin{array}{l}\text { Place confidence intervals around values estimated from the regression } \\
\text { line }\end{array}$ & $\mathrm{X}$ & $X$ \\
\hline $\begin{array}{l}\text { Carry out an analysis of variance to test goodness of fit of the } \\
\text { regression line }\end{array}$ & $\mathrm{X}$ & $\mathrm{X}$ \\
\hline Interpret the results of the tests in terms of the original data & $\mathrm{X}$ & $X$ \\
\hline $\begin{array}{l}\text { Describe the relationship between linear regression and least squares } \\
\text { fitting }\end{array}$ & $\mathrm{X}$ & $\mathrm{X}$ \\
\hline Understand the ideas involved in a multiple regression analysis & $\mathrm{X}$ & $\mathrm{X}$ \\
\hline Appreciate the importance of experimental design & $\mathrm{X}$ & $\mathrm{X}$ \\
\hline Recognize simple statistical designs & $\mathrm{X}$ & $X$ \\
\hline
\end{tabular}


Table 7.6 Outlines of optimization courses at KNRTU-KAI and TUT

\begin{tabular}{l|l|l}
\hline Course information & KNRTU-KAI & TUT \\
\hline Bachelor/master level & Master & Master \\
\hline Preferred year & 2 & 2 \\
\hline Selective/mandatory & Mandatory & Selective \\
\hline Number of credits & 3 & 5 \\
\hline Teaching hours & 43 & 50 \\
\hline Preparatory hours & 65 & 60 \\
\hline Teaching assistants & 1 & 1 \\
\hline Computer labs & Available & Available \\
\hline Average number of students on the course & 20 & 30 \\
\hline Average pass $\%$ & $95 \%$ & $90 \%$ \\
\hline$\%$ of international students & - & $60 \%$ \\
\hline & &
\end{tabular}

\subsubsection{Comparative Analysis on "Optimisation Methods"}

"Optimisation Methods" is a MSc level theoretical course with approximately 20 students ( 1 academic group). Most of them (80\%) are young men. Their ages vary from 20 to 28 years. Most of them are 21 or 22 years old. The course is studied as the second Master's course in the fall semester (third semester). A special feature is that these students have no education in IT-Informatics as their second competence. Teaching the course is carried out at the Department of Applied Mathematics and Computer Science at the Institute of Computer Technology and Information Protection (CTIP). Comparison of this course was conducted with a similar course "Optimisation Methods" by TUT. Outlines of both the courses are presented in Table 7.6.

Optimisation Methods is a mandatory Master's course in the second year of study of the Master's. Prerequisite courses for the Optimisation Methods are: Calculus 13, Linear Algebra, Probability theory and Mathematical Statistics, Graph Theory. These courses are part of the Bachelor's degree.

Since 2011, KNRTU-KAI has started to use LMS Blackboard, which is a learning management system supporting e-learning. The content of educational materials are included in the LMS Blackboard in a form suitable for e-learning.

An e-learning course on Optimisation Methods was developed in the LMS Blackboard environment. Mandatory e-learning components-course schedule, lecture notes, guidelines for tutorials, Computer labs, as well as independent student work. There is also a mandatory component - a test for students on theoretical items of the course. Thus, KNRTU-KAI uses a blended form of learning that combines classroom instruction with students' independent work using the LMS Blackboard environment.

The size of the course is 3 credits, which means on average $108 \mathrm{~h}$ of work ( $36 \mathrm{~h}$ for each credit). The credits are divided among different activities as follows: lectures $10 \mathrm{~h}$, computer labs $20 \mathrm{~h}$, homework $35 \mathrm{~h}, 30 \mathrm{~h}$ for exam preparation and $3 \mathrm{~h}$ for exam. 
About 20 students study this course every year at the Institute of Computer Technology and Information Protection. About $20 \%$ of them are female.

The lectures are theoretically based, but application examples on all the methods and algorithms are shown also, as well. Computer labs use our own computer tutorial "Optimisation methods", which exists on LMS Blackboard, MS Excel and MATLAB are also in use.

Generally, students have to pass one test and complete five individual laboratory workshops during the semesters. When all this work is successfully done, they are allowed to enter an exam. In the exam a student has to answer thoroughly to two questions from random topics, and briefly to answer some additional questions. Prior to this, all the students of a group had to take a pen and paper test of 40 test items, which allows the teacher to determine the readiness of the students for the exam. The final grade is determined by the examiner. The grade depends on how successfully all the parts of the exams were passed, and it takes into account the test results, students' practical work and laboratory work during the semester. The final grade is mathematically dependent on the number of points in accordance with the score-rating system, adopted by the university.

\subsubsection{Contents of the Course}

The comparison is based on the SEFI framework [1]. Prerequisite competencies are presented in Table 7.7. Outcome competencies are given in Tables 7.8 and 7.9.

Table 7.7 Core 0 level prerequisite competencies of the courses on optimization at KNRTU-KAI and TUT

\begin{tabular}{l|l|l}
\hline Core 0 & KNRTU-KAI & TUT \\
\hline Competency & $\mathrm{X}$ & $\mathrm{X}$ \\
\hline Arithmetic of real numbers & $\mathrm{X}$ & $\mathrm{X}$ \\
\hline Algebraic expressions and formulas & $\mathrm{X}$ & $\mathrm{X}$ \\
\hline Linear laws & $\mathrm{X}$ & $\mathrm{X}$ \\
\hline Quadratics, cubics, polynomials & $\mathrm{X}$ & $\mathrm{X}$ \\
\hline Functions and their inverses & $\mathrm{X}$ & $\mathrm{X}$ \\
\hline Logarithmic and exponential functions & $\mathrm{X}$ & $\mathrm{X}$ \\
\hline Rates of change and differentiation & $\mathrm{X}$ & $\mathrm{X}$ \\
\hline Stationary points, maximum and minimum values & $\mathrm{X}$ & $\mathrm{X}$ \\
\hline Definite integration, applications to areas and volumes & $\mathrm{X}$ & $\mathrm{X}$ \\
\hline Proof & $\mathrm{X}$ & \\
\hline Data handling & $\mathrm{X}$ & \\
\hline Probability & &
\end{tabular}


Table 7.8 Core 1 level outcome competencies of the courses on optimization at KNRTU-KAI and TUT

\begin{tabular}{l|l|l}
\hline Core 1 & KNRTU-KAI & TUT \\
\hline Competency & X & \\
\hline Rational functions & X & \\
\hline Hyperbolic functions & With some exceptions ${ }^{\mathrm{a}}$ & $\mathrm{X}$ \\
\hline Functions & $\mathrm{X}$ & $\mathrm{X}$ \\
\hline Differentiation & $\mathrm{X}$ & $\mathrm{X}$ \\
\hline Solution of nonlinear equations & $\mathrm{X}$ & $\mathrm{X}$ \\
\hline Vector algebra and applications & $\mathrm{X}$ & $\mathrm{X}$ \\
\hline Matrices and determinants & & \\
\hline
\end{tabular}

${ }^{a}$ Obtain the first partial derivatives of simple functions of several variables; use appropriate software to produce 3D plots and/or contour maps

Table 7.9 Core 2 level outcome competencies of the courses on optimization at KNRTU-KAI and TUT

\begin{tabular}{l|l|l}
\hline Core 2 & KNRTU-KAI & TUT \\
\hline Competency & X & \\
\hline Ordinary differential equations & With some exceptions $^{\mathrm{a}}$ & $\mathrm{X}$ \\
\hline Functions of several variables &
\end{tabular}

${ }^{a}$ Define a stationary point of a function of several variables; define local maximum, local minimum and saddle point for a function of two variables; locate the stationary points of a function of several variables

Unfortunately SEFI Framework does not describe learning outcomes suitable for "Optimisation Methods". After successful completion of the course at KNRTUKAI, a student should:

- Have experience in using optimization techniques on a PC with Microsoft Windows operating system.

- Be able to formulate basic mathematical optimization problems, depending on the type of quality criteria and availability limitations.

- Be able to solve the problem by the classical method of unconstrained minimization of functions with one and several variables.

- Be able to use the simplex method of linear programming to solve related problems;

- Be able to apply basic numerical methods for solving nonlinear programming in practice.

- Know the fundamentals of modern technologies to develop mathematical models and find optimal solutions.

- Know the classification of extreme problems and methods for solving them.

- Know the main analytical and numerical methods for unconstrained minimization of functions of one and several variables.

- Know the basic methods for solving nonlinear programming problems.

- Know the main algorithms for solving linear programming problems. 


\subsubsection{Summary of the Results}

The comparison has shown the following similarities and differences: In both the universities we use blended learning, however, at TUT significantly more hours are devoted to lectures.

The content of the courses in the universities is very similar: the students acquire knowledge on the main topics of conditional and unconditional optimization and linear programming. In Kazan University the dimensional optimization problem is studied separately.

Concerning the use of computer technology. Both universities use learning management systems for presentation of the lecture material, in TUT is Moodle is used, and KNRTU-KAI uses LMS Blackboard. Both systems provide similar opportunities for students. In both universities laboratory work is conducted in specialized programs: in TUT MATLAB is used, in Kazan a specially designed program. The course "Optimisation methods" does not require extensive modernization. To improve the course the best way is to use Math-Bridge technology.

\subsubsection{Comparative Analysis on "Discrete Mathematics"}

The course "Discrete Mathematics" is designed for Bachelor program "Software Engineering", training profile "Development of software and information systems". The course "Discrete Mathematics" is taught in semesters 2 and 3. In the current academic year 25 students are enrolled on this program on the 2 semester (19 males and 6 females) and 17 students on the 3 semester (11 males and 6 females). The course has been modified to meet the requirements of professional standards of SEFI [1] and implemented in e-learning system Math-Bridge. Modification and development of the e-learning course was carrie out in DFKI by employees group of KNRTU-KAI, who were specially sent there for training and for e-learning course development.

This course was compared with two courses "Discrete Mathematics" and "Algorithm Mathematics" at Tampere University of Technology (TUT), Tampere, Finland. The course outlines can be found in Table 7.10.

Discrete Mathematics is mandatory course for Bachelors of the first and second year of study ( 2 and 3 semesters). Prerequisite courses for the Discrete Mathematics are: Calculus 1-3, Linear Algebra. Since 2011, KNRTU-KAI started to use learning management system LMS Blackboard. The course material for the e-learning courses are in the LMS Blackboard environment. For Discrete Mathematics an elearning course was developed into the LMS Blackboard environment. Mandatory e-learning components-course schedule, lecture notes, guidelines for tutorials, computer labs, as well as for independent work of students. There is also a mandatory component-test items for students on the theoretical material of course. Thus, KNRTU-KAI uses a blended form of education that combines classroom instruction with independent work of students in LMS Blackboard. 
Table 7.10 Outlines of discrete and algorithm mathematics courses at KNRTU-KAI and TUT

\begin{tabular}{l|l|l}
\hline Course information & KNRTU-KAI & TUT \\
\hline Bachelor/master level & Bachelor & Bachelor \\
\hline Preferred year & 1 and 2 & 2 \\
\hline Selective/mandatory & Mandatory & Mandatory \\
\hline Number of credits & 12 & $4+4$ \\
\hline Teaching hours & 180 & $49+42$ \\
\hline Preparatory hours & 252 & $65+65$ \\
\hline Teaching assistants & 1 & $1-3$ \\
\hline Computer labs & No & \\
\hline Average number of students on the course & 50 & 150 \\
\hline Average pass \% & $85 \%$ & $85 \%$ \\
\hline$\%$ of international students & $10 \%$ & \\
\hline & &
\end{tabular}

The course size is 12 credits, which means on average $432 \mathrm{~h}$ of work ( $36 \mathrm{~h}$ for each credit). The credits are divided among different activities as follows: lectures $108 \mathrm{~h}$, tutorials $72 \mathrm{~h}$, homework $252 \mathrm{~h}$, and $72 \mathrm{~h}$ for exam preparation.

About 50 students are learning for these course every year at the Institute of Computer Technology and Information Protection. About $20 \%$ of them are female.

The lectures are theoretically based, but application examples of every method and algorithm are shown as well. Computer labs use LMS Blackboard, MS Excel and MATLAB.

Generally our students have to pass 4 tests and execute 36 tutorials during the two semesters. When all this work is successfully done, they are allowed to pass an exam. The students have to answer in detail two questions from random topics, and briefly answer some additional questions. Prior to this, all the students have written answers to a test of 15 test items, which allows one to determine the readiness of a student for the exam. The final grade is determined by the examiner depending on how successfully all the parts of the exams were passed. It takes into account the results of the tests, practical work and laboratory work during the semester. The final grade is mathematically dependent on the number of points in accordance with the score-rating system, adopted by the university. The score-rating system is the following:

- less than 50 points is unsatisfactory (grade “2”),

- from 50 to 69 points is satisfactory (grade “ 3 "),

- from 70 to 84 is good (grade “4”),

- more than 84 is excellent (grade "5").

Our course is supported by the following educational software and TEL tools: MATLAB and Excel are used in tutorials to solving some problems and e-Learning Systems LMS Blackboard platform for testing the students' knowledge on our course.

In the next academic year (from fall semester 2017) we will use the international intellectual Math-Bridge system for training and monitoring abilities to solve 
problems of Discrete Mathematics in the trial operation of the system in accordance with the project MetaMath.

\subsubsection{Contents of the Course}

The comparison is based on the SEFI framework [1]. Prerequisite competencies are presented in Table 7.11. Outcome competencies are given in Tables 7.12, 7.13, 7.14, and 7.15 .

Table 7.11 Core 0 level prerequisite competencies of the discrete and algorithm mathematics courses at KNRTU-KAI and TUT

\begin{tabular}{l|l|l}
\hline Core 0 & KNRTU-KAI & TUT \\
\hline Competency & $\mathrm{X}$ & $\mathrm{X}$ \\
\hline Arithmetic of real numbers & $\mathrm{X}$ & $\mathrm{X}$ \\
\hline Algebraic expressions and formulas & $\mathrm{X}$ & $\mathrm{X}$ \\
\hline Linear laws & $\mathrm{X}$ & $\mathrm{X}$ \\
\hline Quadratics, cubics, polynomials & $\mathrm{X}$ & $\mathrm{X}$ \\
\hline Functions and their inverses & $\mathrm{X}$ & $\mathrm{X}$ \\
\hline Logarithmic and exponential functions & $\mathrm{X}$ & $\mathrm{X}$ \\
\hline Rates of change and differentiation & $\mathrm{X}$ & $\mathrm{X}$ \\
\hline Stationary points, maximum and minimum values & $\mathrm{X}$ & $\mathrm{X}$ \\
\hline Definite integration, applications to areas and volumes & $\mathrm{X}$ & $\mathrm{X}$ \\
\hline Proof & $\mathrm{X}$ & $\mathrm{X}$ \\
\hline Data handling & $\mathrm{X}$ & - \\
\hline Probability & &
\end{tabular}

Table 7.12 Core 0 level outcome competencies of the discrete and algorithm mathematics courses at KNRTU-KAI and TUT

\begin{tabular}{l|l|l}
\hline Core 0 & KNRTU-KAI & TUT \\
\hline Competency & X & X \\
\hline Sets &
\end{tabular}

Table 7.13 Core 1 level outcome competencies of the discrete and algorithm mathematics courses at KNRTU-KAI and TUT

\begin{tabular}{l|l|l}
\hline Core 1 & KNRTU-KAI & TUT \\
\hline Competency & $\mathrm{X}$ & $\mathrm{X}$ \\
\hline Mathematical logic & With some exceptions ${ }^{\mathrm{a}}$ & $\mathrm{X}$ \\
\hline Sets & $\mathrm{X}$ & $\mathrm{X}$ \\
\hline Mathematical induction and recursion & $\mathrm{X}$ & $\mathrm{X}$ \\
\hline Graphs & $\mathrm{X}$ & \\
\hline Combinatorics & & \\
\hline
\end{tabular}

${ }^{\mathrm{a}}$ Compare the algebra of switching circuits to that of set algebra and logical connectives; analyze simple logic circuits comprising AND, OR, NAND, NOR and EXCLUSIVE OR gates 
Table 7.14 Core 2 level outcome competencies of the discrete and algorithm mathematics courses at KNRTU-KAI and TUT

\begin{tabular}{|c|c|c|}
\hline \multicolumn{3}{|l|}{ Core 2} \\
\hline Competency & KNRTU-KAI & TUT \\
\hline Number system & With some exceptions ${ }^{\mathrm{a}}$ & $\mathrm{X}$ \\
\hline Algebraic operators & $\mathrm{X}$ & \\
\hline Recursion and difference equations & With some exceptions ${ }^{b}$ & $\mathrm{X}$ \\
\hline Relations & $\mathrm{X}$ & $\mathrm{X}$ \\
\hline Graphs & $X$ & $X$ \\
\hline Algorithms & With some exceptions ${ }^{\mathrm{c}}$ & $\mathrm{X}$ \\
\hline \multicolumn{3}{|c|}{$\begin{array}{l}{ }^{\text {a }} \text { Carry out arithmetic operations in the binary system } \\
{ }^{b} \text { Define a sequence by a recursive formula } \\
{ }^{c} \text { Understand when an algorithm solves a problem; understand the worst case analysis of an } \\
\text { algorithm; understand the notion of an NP-complete problem (as a hardest problem among NP } \\
\text { problems) }\end{array}$} \\
\hline
\end{tabular}

Table 7.15 Core 3 level outcome competencies of the discrete and algorithm mathematics courses at KNRTU-KAI and TUT

\begin{tabular}{l|l|l}
\hline Core 3 \\
\hline Competency & KNRTU-KAI & TUT \\
\hline Combinatorics & $\mathrm{X}$ & \\
\hline Graph theory & $\mathrm{X}$ & \\
\hline
\end{tabular}

\subsubsection{Summary of the Results}

In KNRTU-KAI for the study of the course "Discrete Mathematics" four times more hours allotted than at the Tampere University of Technology. This is due to the fact that this item in KNRTU-KAI is studied for two semesters and only one semester in TUT. As a consequence, many of the topics that are covered in KNRTUKAI not covered in TUT. In the course "Discrete mathematics" a lot of attention in both universities given to sections related to mathematical logical expressions and algebraic structures. This is useful for students who will continue to study subjects such as "Theory of Algorithms" and "Logic". The TUT students are being prepared with the help of the Moodle e-learning environment. Moodle also helps to gather feedback from students after the course. In KNRTU-KAI it is not used. This experience is very useful.

In general, course "Discrete Mathematics" by KNRTU-KAI is rather good and meets the requirements for IT-students teaching. But it will be useful to make the course some more illustrative by using computer-based training systems. As a result the course "Discrete Mathematics" has been modernized and the e-learning training course was developed in Math-Bridge system. 


\subsection{Analysis of Mathematical Courses in LETI}

Mikhail Kuprianov and Iurii Baskakov and Sergey Pozdnyakov and Sergey Ivanov and Anton Chukhnov and Andrey Kolpakov and Vasiliy Akimushkin

Saint Petersburg State Electrotechnical University (LETI), Saint Petersburg, Russia e-mail: mskupriyanov@mail.ru; bosk@bk.ru; sg_ivanov@mail.ru

Ilya Posov

Saint Petersburg State Electrotechnical University (LETI), Saint Petersburg, Russia Saint Petersburg State University (SPbU), Saint Petersburg, Russia

Sergey Rybin

Saint Petersburg State Electrotechnical University (LETI), Saint Petersburg, Russia ITMO University, Department of Speech Information Systems, Saint Petersburg, Russia

\subsubsection{Saint Petersburg State Electrotechnical University (LETI)}

Saint Petersburg State Electrotechnical University (LETI) was founded in 1886 as a technical college of the post and telegraph department. In 1891 it gained the state of an institute. The first elected university director was the Russian-born scientist A.S. Popov, who is one of the people credited for inventing the radio. From its founding LETI was a center of Russian electrical engineering. Many outstanding Russian scientists have worked there over the years. After the October Revolution, in 1918, the institution was renamed Leningrad Electrotechnical Institute (LETI).

In the 1920s, LETI played a significant role in the development of electrification plans of Russia. After the Second World War, intensive developments of new scientific fields were started at the institute: radio electronics and cybernetics, electrification and automatization of industrial equipment, automatics and telemechanics, computer science and optoelectronics.

In 1991 the institute was renamed after the city and became Saint-Petersburg Electrotechnical Institute. However, it kept Lenin's name in its title. In early 1990s the Faculty of Humanities was founded, and the Institute was granted university status and was renamed again into "V.I.Ulyanov (Lenin) Saint-Petersburg State Electrotechnical University". In 1998 it was renamed for the current name.

Despite having a faculty of humanities and faculty of economics and management in its structure, LETI should be considered as a technical university. The other five of seven main faculties are completely devoted to engineering and computer science specializations.

There is also an Open Faculty (OF) for evening and correspondence students for all specializations. Other faculties, which are the Faculty of Military Education and the newly created Faculty of Common Training do not have their own students; 
Table 7.16 Outlines of mathematical logics and theory of algorithms courses at LETI (ML\&TA) and TUT (AM)

\begin{tabular}{l|l|l}
\hline Course information & LETI & TUT \\
\hline Bachelor/master level & Bachelor & Bachelor \\
\hline Preferred year & 1 & 2 \\
\hline Selective/mandatory & Both & Both \\
\hline Number of credits & 5 & 4 \\
\hline Teaching hours & 40 & 49 \\
\hline Preparatory hours & 65 & 65 \\
\hline Teaching assistants & No & $1-2$ \\
\hline Computer labs & Available & Available \\
\hline Average number of students on the course & 400 & 150 \\
\hline Average pass \% & $85 \%$ & $90 \%$ \\
\hline$\%$ of international students & $20 \%$ & Less than 5\% \\
\hline
\end{tabular}

they teach students from other faculties. International Student Office works with foreign students, including teaching them Russian. Finally, the Faculty of Retraining and Raising the Level of Skills does not work with students at all, it works with university personnel.

Currently there are more than 8200 students in the university. Most of them (more than 7500) are technical (STEM) students. Totally at five faculties there are 17 Bachelor and 13 Master STEM programs, also there is one Specialist (specific Russian 5-year grade) program at FCTI.

Mathematical education in LETI is divided between two departments: Department of Higher Mathematics-1 and -2 .

\subsubsection{Comparative Analysis of "Mathematical Logics and Theory of Algorithms" (ML\&TA)}

"Mathematical Logics and Theory of Algorithms" is a more theoretical course. There are around 400 second year students from all 6 Bachelor and 1 Specialist FCTI programs studying this course. All of them are supposed to be applied specializations, but, of course, each program contains a lot of theoretical courses. The course outlines with the corresponding course from Tampere University of Technology (TUT) "Algorithm Mathematics" are given in Table 7.16.

ML\&TA is mandatory Bachelor level course of the second year. Its prerequisite courses are Discrete Mathematics; Linear Algebra and Calculus 1-2. The follow-up courses are Programming and various special courses from all seven FCTI Bachelor programs.

The department responsible for the course is the Department of Higher Mathematics-2. Now the University is in the process of restructuring and probably the next year two departments of mathematics will be joined, but for purpose of teaching FCTI students a new Department of Algorithm Mathematics will be 
founded. It will be responsible for this course and also for the prerequisite course of Discrete Mathematics.

The overall number of credits is 5 . In Russia we have $36 \mathrm{~h}$ in $1 \mathrm{credit}$, so the total amount is $180 \mathrm{~h}$ for this course. Among them $36 \mathrm{~h}$ of lectures, $36 \mathrm{~h}$ of tutorials, $72 \mathrm{~h}$ of homework and $36 \mathrm{~h}$ of exam preparation. There are about 400 students studying the course every year. About $20 \%$ of them are foreign students and about $30 \%$ are female.

The lectures are theoretically based, but applications of every theorem and algorithm are shown. Tutorial classes are completely devoted to solving problems, but generally with pen and paper, without computers. However, some of the algorithms are to be implemented by students while studying this course, and almost all of these are used later while passing the follow-up courses. We also offer some students an alternative way to pass an exam by creating a computer program.

The course is generally oriented to individual work. However, group work can be episodically introduced as an experiment.

Generally our students have to pass two tests and complete three individual homeworks during the semester. When all this work is successfully done, they are allowed to enter an exam. The examination system depends on the lecturer: oral or written. The oral exam is a classic Russian form of examination where the student is to answer thoroughly two questions from random topics, solve a problem and briefly answer some additional questions.

The final mark is determined by the examiner depending on how successfully all the parts of the exams were passed. The written exam consists of several problems which are to be solved by students. The final mark mathematically depends on the solved problems ratio. In both cases the final mark belongs to the classic Russian system: from 2 (failed) to 5 (excellent).

Our course is supported by the following TEL tools: Problem generators can create a huge amount of variants of one problem using one or few certain template(s) and changing numbers, letters etc. Of course, this is support for teachers activity, not for students. Google sites are used by teacher and students to exchange information. For example, students can submit some homeworks to the teacher using this sites. The TEL systems were not generally used in this course before the MetaMath project. Introducing TEL systems (Moodle and our own subject manipulators) is the main direction of our course modification.

\subsubsection{Contents of the Course}

The comparison is based on the SEFI framework [1]. Prerequisite competencies are presented in Table 7.17. Outcome competencies are given in Tables 7.18, 7.19, 7.20, 7.21, and 7.22. 
Table 7.17 Prerequisite competencies of mathematical logics and theory of algorithms courses at LETI (ML\&TA) and TUT (AM)

\begin{tabular}{l|l|l}
\hline Core 1 & LETI & TUT \\
\hline Competency & $\mathrm{X}$ & $\mathrm{X}$ \\
\hline Arithmetic of real numbers & $\mathrm{X}$ & $\mathrm{X}$ \\
\hline Algebraic expressions and formulas & $\mathrm{X}$ & $\mathrm{X}$ \\
\hline Linear laws & $\mathrm{X}$ & $\mathrm{X}$ \\
\hline Quadratics, cubics, polynomials & $\mathrm{X}$ & $\mathrm{X}$ \\
\hline Functions and their inverses & $\mathrm{X}$ & $\mathrm{X}$ \\
\hline Sequences, series, binomial expansions & $\mathrm{X}$ & $\mathrm{X}$ \\
\hline Logarithmic and exponential functions & $\mathrm{X}$ & $\mathrm{X}$ \\
\hline Proof & $\mathrm{X}$ & $\mathrm{X}$ \\
\hline Sets & &
\end{tabular}

Table 7.18 Core 1 level prerequisite competencies of mathematical logics and theory of algorithms courses at LETI (ML\&TA) and TUT (AM)

\begin{tabular}{l|l|l}
\hline Core 1 & LETI & TUT \\
\hline Competency & With some exceptions ${ }^{\mathrm{a}}$ & $\mathrm{X}$ \\
\hline Sets & $\mathrm{X}$ & $\mathrm{X}$ \\
\hline Mathematical induction and recursion & $\mathrm{X}$ & \\
\hline Graphs & $\mathrm{X}$ & $\mathrm{X}$ \\
\hline Matrices and determinants & $\mathrm{X}$ &
\end{tabular}

${ }^{a}$ Excluding logical circuits

Note: sometimes graphs are completely included in Discrete Mathematics, then they should be considered as prerequisites. In other cases they are divided between courses of DM and ML\&TA, and then they should be partially considered as outcomes

Table 7.19 Core 2 level prerequisite competencies of mathematical logics and theory of algorithms courses at LETI (ML\&TA) and TUT (AM)

\begin{tabular}{l|l|l}
\hline Core 2 & \multicolumn{2}{l}{} \\
\hline Competency & LETI & TUT \\
\hline Number systems & $\mathrm{X}$ & \\
\hline Algebraic operations & Excluding hamming code & $\mathrm{X}$ \\
\hline Relations & Excluding inverse binary relations and ternary relations & $\mathrm{X}$ \\
\hline
\end{tabular}

Note: Binary relations sometimes are included in Discrete Mathematics, so they are considered as prerequisites; in other cases they are included in ML\&TA and so they are outcome competences

Table 7.20 Core 1 level outcome competencies of mathematical logics and theory of algorithms courses at LETI (ML\&TA) and TUT (AM)

\begin{tabular}{l|l|l}
\hline Core 1 & LETI & TUT \\
\hline Competency & $\mathrm{X}$ & $\mathrm{X}$ \\
\hline Mathematical logic & $\mathrm{X}$ & \\
\hline Graphs & & \\
\hline
\end{tabular}


Table 7.21 Core 2 level outcome competencies of mathematical logics and theory of algorithms courses at LETI (ML\&TA) and TUT (AM)

\section{Core 2}

\begin{tabular}{l|l|l}
\hline Competency & LETI & TUT \\
\hline Relations & Excluding inverse binary relations and ternary relations & $\mathrm{X}$ \\
\hline Algorithms & $\mathrm{X}$ & $\mathrm{X}$ \\
\hline
\end{tabular}

Note: Binary relations sometimes are included in Discrete Mathematics, so they are considered as prerequisites; in other cases they are included in ML\&TA and so they are outcome competences

Table 7.22 Core 3 level outcome competencies of mathematical logics and theory of algorithms courses at LETI (ML\&TA) and TUT (AM)

\begin{tabular}{|c|c|c|}
\hline \multicolumn{3}{|l|}{ Core 3} \\
\hline Competency & LETI & TUT \\
\hline Find the distance (shortest way) between two vertices in a graph & $\mathrm{X}$ & \\
\hline Find a the graph and his matrix for a relation & $\mathrm{X}$ & \\
\hline Use topological sort algorithm and transitive closure algorithms & $\mathrm{X}$ & \\
\hline Understand the concept of Boolean function & $\mathrm{X}$ & $\mathrm{X}$ \\
\hline Construct a truth table for a function & $\mathrm{X}$ & $\mathrm{X}$ \\
\hline Obtain CNF and DNF of a function & $\mathrm{X}$ & \\
\hline Obtain Zhegalkin polynomial of a function & $\mathrm{X}$ & \\
\hline Build a composition of two or more functions in different forms & $\mathrm{X}$ & \\
\hline Recognize function membership in one of the post classes & $\mathrm{X}$ & \\
\hline Use post criteria for a set of functions & $\mathrm{X}$ & \\
\hline Recognize context-free grammar & $X$ & \\
\hline Construct context-free grammar for a simple language & $\mathrm{X}$ & \\
\hline Build a parser for a grammar using Virt algorithm & $\mathrm{X}$ & \\
\hline Recognize table and graph representation of final state machine & $\mathrm{X}$ & \\
\hline Recognize automata language & $\mathrm{X}$ & \\
\hline Carry out set operations with automata languages & $\mathrm{X}$ & \\
\hline Obtain FSM for regular expression and vice versa & $\mathrm{X}$ & \\
\hline Obtain determined FSM for non-determined one & $\mathrm{X}$ & \\
\hline FSM minimization & $\mathrm{X}$ & \\
\hline Understand the notion of a turing machine & $\mathrm{X}$ & \\
\hline Run simple turing machines on paper & $\mathrm{X}$ & \\
\hline Construct simple turing machine & $\mathrm{X}$ & \\
\hline Run Markov algorithm & $\mathrm{X}$ & \\
\hline Recognize the prenex and Skolem form of first-order formulas & $\mathrm{X}$ & \\
\hline Obtain the prenex and Skolem form for a certain formula & $\mathrm{X}$ & \\
\hline Unify first-order logic formulas & $\mathrm{X}$ & \\
\hline Use resolution method for propositions and first-order logic & $\mathrm{X}$ & \\
\hline
\end{tabular}




\subsubsection{Summary of the Results}

The comparison shows that both courses cover generally the same topics and competences. However LETI ML\&TA course contains more competences than the corresponding Algorithm Mathematics course in TUT. It follows from two main reasons: first, in LETI the course has more credits and hours; and second, LETI course is more intensive which is good for gifted students and may be probably be not so good for some others. This conclusion does not lead to any course modifications just because we do not want to reduce our course.

The second conclusion is that TUT's course is more applied and uses more TEL systems. There is space for modifications of our course. The main idea of modification is to introduce Moodle in our course and add there as much as possible lectures, test and laboratory works which could help our students to get closer to understanding of our course through their self-activity on the internet.

\subsection{Analysis of Mathematical Courses in UNN}

Dmitry Balandin and Oleg Kuzenkov and Vladimir Shvetsov

Lobachevsky State University of Nizhny Novgorod (UNN), Nizhny Novgorod, Russia

e-mail: dbalandin@yandex.ru; kuzenkov_o@mail.ru; shvetsov@unn.ru

\subsubsection{Lobachevsky State University of Nizhni Novgorod (UNN)}

The Lobachevsky State University of Nizhni Novgorod (UNN) is one of the leading classical research universities in Russia established in 1916. The university provides fundamental education in accordance with the best traditions of Russian Higher Education.

By the decision of the Russian Government, in 2009 UNN was awarded the prestigious status of a National Research University.

Being an innovative university, the University of Nizhni Novgorod provides high-quality research-based education in a broad range of academic disciplines and programs. The combination of high educational quality and accessibility of education due to a great variety of educational program types and forms of training is a distinctive feature of the University in today's global knowledge economy.

UNN is ranked 74 by the QS World University Ranking BRICS, and it has five QS Stars for excellence in Teaching, Employability, Innovation, and Facilities. UNN is one of only 15 Russian universities awarded in 2013 with a prestigious grant of the Government of the Russian federation to implement the Leading Universities International Competitiveness Enhancement Program. 
Holding leading positions among Russian universities, it is a worldwide recognized institute of higher education: UNN is represented in the Executive Board of the Deans European Academic Network (DEAN), it is a member of the European University Association (EUA) and has direct contractual relations with more than 20 foreign educational and research centers.

The UNN has been implementing a great number of international projects, funded by the European Commission, IREX (the International Research \& Exchanges Board), National Fund for Staff Training and other widely known organizations. The University also closely cooperates with the institutes of the Russian Academy of Sciences and the largest transnational high-tech companies (Microsoft, Intel etc.).

At present about 40,000 students and post-graduate students from more than 65 countries of the world are studying at UNN, about half of which pursue STEM courses. Training on all educational programs is conducted by a highly qualified teaching staff, over $70 \%$ of them having a PhD or Doctor of Science degrees.

Lobachevsky State University of Nizhni Novgorod as a National Research University has been granted the right to develop its own self-imposed educational standards (SIES). In 2010, the first UNN standard was developed in the area of studies "010300 Fundamental Computer Science and Information Technology (FCSIT)" (Bachelor's degree). In 2011, the second UNN standard was developed in the area of studies "Applied Computer Science" (ACS) (Bachelor's degree).

The Bachelor's program "Information Technologies", is aimed at training experts in high-level programming for hi-tech companies of the information industry.

UNN is engaged in successful cooperation with major international IT companies like Intel, Microsoft, IBM, Cisco Systems, NVIDIA that provide the University with advanced computer equipment and software. This ensures that the educational process is based on the latest achievements in this field of science and technology. At the University, there are research laboratories established with the support of Intel Corporation as well as educational centers of Microsoft and Cisco Systems. In 2005 Bill Gates, president of Microsoft Corporation, named the University of Nizhni Novgorod among the world's ten leading universities in the field of high-performance computing. In 2013 UNN built the powerful supercomputer "Lobachevsky", which is the second fastest supercomputer in Russia.

Teachers, working in this program, are all recognized experts in various fields of science, Doctors and Candidates of Science. The program of studies in Information Technologies is envisaged by Computing Curricula 2001 recommended by such international organizations as IEEE-CS and ACM.

Graduates of the Bachelor's program "Fundamental Computer Science and Information Technologies", are prepared for the following activities in their professional sphere:

- scientific and research work in the field of theoretical computer sciences, as well as development of new information technologies;

- design and application of new information technologies, realized in the form of systems, products and services; 
- application of information technologies in project designing, management and financial activities.

In 2014, UNN educational program in the area of studies "010300 Fundamental Computer Science and Information Technology (FCSIT)” (Bachelor's degree) received the accreditation of Russian Engineer Education Association. As a rule, UNN IT-students study in 3 groups with 20 students in each one. Mean age is 17 . Male students are twice as many as females. Moreover, there is one group with 20 foreign students (Asia, Africa), who study in English.

\subsubsection{Comparative Analysis of "Mathematical Analysis"}

Mathematical Analysis (Calculus) is included in curricula as one of the core subjects of mathematics with their own distinct style of reasoning. Mathematical Analysis is ubiquitous in natural science and engineering, so the course is valuable in conjunction with Engineering majors. The purpose of the course is to provide a familiarity to concepts of the real analysis, such as limit, continuity, differentiation, connectedness, compactness, convergence etc. The number of students is 60 . It is a mandatory course in UNN that combines both theoretical and applied approaches. Mathematics plays key role in the course and this course forms a foundation for several other applied special disciplines in corresponding educational programs. Mathematical Analysis contains three parts corresponding to the semesters of study: Mathematical Analysis I, II, and III.

Mathematical Analysis I contains such topics as basic properties of inverse, exponential, logarithmic and trigonometric functions; limit, continuity and derivative of a function, evaluating rules of a derivative, function research and curve-sketching techniques, applications of derivative in the optimization problems, L'Hôpital's rule. Mathematical Analysis II contains such topics as indefinite and definite integral and their properties, rules of integration, integration of rational functions, evaluating area between curves and surface area using integrals, integrals application in physics, functions of several variables, implicit functions. Mathematical Analysis III contains such topics as theory of number series and functional series, Fourier series, double integrals and further multiple integrals, line and surface integrals.

There are three comparisons: first UNN Mathematical Analysis I (MAI) and Tampere University of Technology (TUT) Engineering Mathematics 1 (EM1), second UNN Mathematical Analysis II (MAII) and TUT Engineering Mathematics 3 (EM3), and third UNN Mathematical Analysis III (MAIII) and TUT Engineering mathematics 4 (EM4). The course outlines are seen in Tables 7.23, 7.24, and 7.25, respectively.

There are no prerequisite courses. The follow-up course for Mathematical Analysis is Differential Equations. In UNN this course is included in the group of core mandatory mathematical courses of the corresponding educational programs. 
Table 7.23 Outlines of MAI (UNN) and EM1 (TUT) courses

\begin{tabular}{l|l|l}
\hline Course information & UNN & TUT \\
\hline Bachelor/master level & Bachelor & Bachelor \\
\hline Preferred year & 1 & 1 \\
\hline Selective/mandatory & Mandatory & Mandatory \\
\hline Number of credits & 6 & 5 \\
\hline Teaching hours & 108 & 57 \\
\hline Preparatory hours & 180 & 76 \\
\hline Teaching assistants & 3 & $1-3$ \\
\hline Computer labs & No & Available \\
\hline Average number of students on the course & 72 & 200 \\
\hline Average pass \% & $90 \%$ & $90 \%$ \\
\hline$\%$ of international students & $25 \%$ & Less than 5\% \\
\hline & &
\end{tabular}

Table 7.24 Outlines of MAII (UNN) and EM3 (TUT) courses

\begin{tabular}{l|l|l}
\hline Course information & UNN & TUT \\
\hline Bachelor/master level & Bachelor & Bachelor \\
\hline Preferred year & 1 & 1 \\
\hline Selective/mandatory & Mandatory & Mandatory \\
\hline Number of credits & 6 & 5 \\
\hline Teaching hours & 108 & 62 \\
\hline Preparatory hours & 180 & 76 \\
\hline Teaching assistants & 3 & $1-3$ \\
\hline Computer labs & No & Available \\
\hline Average number of students on the course & 72 & 200 \\
\hline Average pass \% & $90 \%$ & $90 \%$ \\
\hline$\%$ of international students & $25 \%$ & Less than 5\% \\
\hline
\end{tabular}

Table 7.25 Outlines of MAIII (UNN) and EM4 (TUT) courses

\begin{tabular}{l|l|l}
\hline Course information & UNN & TUT \\
\hline Bachelor/master level & Bachelor & Bachelor \\
\hline Preferred year & 2 & $1-2$ \\
\hline Selective/mandatory & Mandatory & Selective \\
\hline Number of credits & 8 & 4 \\
\hline Teaching hours & 144 & 49 \\
\hline Preparatory hours & 72 & 57 \\
\hline Teaching assistants & 3 & $1-2$ \\
\hline Computer labs & No & Available \\
\hline Average number of students on the course & 65 & 150 \\
\hline Average pass $\%$ & $90 \%$ & $85 \%$ \\
\hline$\%$ of international students & $25 \%$ & Less than 5\% \\
\hline & &
\end{tabular}


Teaching the course in UNN is more theory-based and unfortunately does not include any innovative pedagogical methods and tools such as: blended learning, flipped classroom, MOOCs, project-based learning, inquiry-based learning, collaborative learning, etc. In TUT on the other hand one can find blended learning, collaborative learning, project-based approach and active use of modern TEL tools for administration, teaching and assessment purposes. Not all modern pedagogical technologies are used in TUT but those of them that do exist in educational process are applied widely and successfully.

The overall number of hours and credits in Mathematical Analysis I, II, and III is $20 \mathrm{cu} .=720 \mathrm{~h}$. It consists of $202 \mathrm{~h}$ lectures, $183 \mathrm{~h}$ tutorials and $200 \mathrm{~h}$ independent work (homework) and $135 \mathrm{~h}$ control of independent work (exams) There are two types of homework assignments: these are problems which arise while lecturing, assigned almost every class day and set of problems assigned during practical lessons (weekly). Tests and exams are conducted some times per each term in written, electronic, and oral forms.

There are the following types of assessment used in UNN: positive (perfect, excellent, very good, good, satisfactory); or negative (unsatisfactory, poor). For perfect, the student displays in-depth knowledge of the main and additional material without any mistakes and errors, can solve non-standard problems, has acquired all the competences (parts of competences) relating to the given subject in a comprehensive manner and above the required level. A stable system of competences has been formed, interrelation with other competences is manifested.

For excellent grade, the student displays in-depth knowledge of the main material without any mistakes and errors, has acquired all the competences (parts of competences) relating to the given subject completely and at a high level, a stable system of competences has been formed. For very good grade, the student has sufficient knowledge of the main material with some minor mistakes, can solve standard problems and has acquired completely all the competences (parts of competences) relating to the given subject. For good grade, the student has the knowledge of the main material with some noticeable mistakes and has acquired in general the competences (parts of competences) relating to the given subject.

For satisfactory grade the student has the knowledge of the minimum material required in the given subject, with a number of errors, can solve main problems, the competences (parts of competences) relating to the subject are at the minimum level required to achieve the main learning objectives. If the grade is unsatisfactory, the knowledge of the material is insufficient, additional training is required, the competences (parts of competences) relating to the subject are at a level that is insufficient to achieve the main learning objectives. Finally, for poor grade, there is lack of knowledge of the material, and relevant competences have not been acquired.

There are two midterm exams (tests) at the end of the first and second semesters and there is a final exam (test) at the end of the third semester. 


\subsubsection{Contents of the Course}

The course comparison is based on the SEFI framework [1]. Prerequisite competencies of the MAI and EM1 courses are given in Table 7.26. Core 1, core 1, core 2, and core 3 outcome competencies for MAI and EM1, MAII and EM3, MAIII and EM4, are given in Tables 7.26, 7.27, 7.28, 7.29, 7.30, 7.31, and 7.32.

Table 7.26 Core 0 level prerequisite competencies of the MAI (UNN) and EM1 (TUT) courses

Table 7.27 Core 1 level outcome competencies of the MAI (UNN) and EM1 (TUT) courses

Table 7.28 Core 0 level outcome competencies of MAII (UNN) and EM3 (TUT) courses

Table 7.29 Core 1 level outcome competencies of MAII (UNN) and EM3 (TUT) courses

Table 7.30 Core 2 level outcome competencies of MAII (UNN) and EM3 (TUT) courses

\begin{tabular}{l|l|l}
\hline Core 0 & UNN & TUT \\
\hline Competency & $\mathrm{X}$ & $\mathrm{X}$ \\
\hline Functions and their inverses & $\mathrm{X}$ & $\mathrm{X}$ \\
\hline Progressions, binomial expansions & $\mathrm{X}$ & $\mathrm{X}$ \\
\hline Logarithmic and exponential functions & $\mathrm{X}$ & $\mathrm{X}$ \\
\hline Rates of change and differentiation & $\mathrm{X}$ & $\mathrm{X}$ \\
\hline Maximum and minimum values & $\mathrm{X}$ & \\
\hline Proof & &
\end{tabular}

\begin{tabular}{l|l|l}
\hline Core 1 & \multicolumn{2}{l}{} \\
\hline Competency & UNN & TUT \\
\hline Hyperbolic functions & $\mathrm{X}$ & $\mathrm{X}$ \\
\hline Rational functions & $\mathrm{X}$ & $\mathrm{X}$ \\
\hline Functions & $\mathrm{X}$ & $\mathrm{X}$ \\
\hline Differentiations & $\mathrm{X}$ & $\mathrm{X}$ \\
\hline Sequences and series & Only sequences & In EM3 \\
\hline
\end{tabular}

\begin{tabular}{l|l|l}
\hline Core 0 & \multicolumn{3}{l}{} \\
\hline Competency & UNN & TUT \\
\hline Indefinite integral & X & X \\
\hline Definite integral, applications & X & X \\
\hline
\end{tabular}

\begin{tabular}{l|l|l}
\hline Core 1 \\
\hline Competency & UNN & TUT \\
\hline Methods of integration & X & X \\
\hline Application of integration & X & X \\
\hline
\end{tabular}

\begin{tabular}{l|l|l}
\hline Core 2 & \multicolumn{3}{|l}{} \\
\hline Competency & UNN & TUT \\
\hline Functions of several variables & X & In EM4 \\
\hline Nonlinear optimization & X & \\
\hline Fourier series & $\mathrm{X}$ & \\
\hline
\end{tabular}


Table 7.31 Core 1 level outcome competencies of MAIII (UNN) and EM4 (TUT) courses

Table 7.32 Core 2 level outcome competencies of the MAIII (UNN) and EM4 (TUT) courses

\begin{tabular}{|c|c|c|c|}
\hline \multicolumn{4}{|l|}{ Core 1} \\
\hline Competency & \multicolumn{2}{|l|}{ UNN } & TUT \\
\hline Sequences and series & \multicolumn{2}{|c|}{ Only series } & In EM3 \\
\hline \multicolumn{4}{|l|}{ Core 2} \\
\hline \multicolumn{2}{|l|}{ Competency } & UNN & \begin{tabular}{l|l}
$\mathrm{N}$ & $\mathrm{TUT}$ \\
\end{tabular} \\
\hline \multicolumn{2}{|c|}{ Function of several variables } & & $\mathrm{X}$ \\
\hline \multicolumn{2}{|l|}{ Nonlinear optimization } & & $\mathrm{X}$ \\
\hline \multicolumn{2}{|l|}{ Fourier series } & $\mathrm{X}$ & \\
\hline \multicolumn{2}{|l|}{ Double integrals } & $\mathrm{X}$ & $\mathrm{X}$ \\
\hline \multicolumn{2}{|c|}{ Further multiple integrals } & $\mathrm{X}$ & $\mathrm{X}$ \\
\hline \multicolumn{2}{|l|}{ Vector calculus } & $\mathrm{X}$ & \\
\hline \multicolumn{2}{|c|}{ Line and surface integrals } & $\mathrm{X}$ & \\
\hline
\end{tabular}

\subsubsection{Summary of the Results}

Comparative analysis shows that thematic content and learning outcomes for both universities are quite close. The difference is observed in the number of hours. The total number of hours is about 700 in UNN, whereas in TUT it is about 400. New information technologies and, in particular, e-learning systems are actively used in TUT. This allows TUT to take out some of the material for independent study and focus on really difficult topics of the discipline. E-learning systems also allow one to automate and, as a result, simplify the knowledge assessment process. In UNN these information technologies are occasionally used some times per semester. UNN established pre- and posttest to control incoming and outcoming students' knowledge in mathematical analysis. The electronic course in the Moodle system is implemented for teaching mathematical analysis for students in study programs AMCS and FCSIT (Applied Mathematics and Computer Sciences, Fundamental Computer Sciences and Information Technologies, respectively). All tests are based on SEFI competences; they contain a large amount of simple tasks (during $60 \mathrm{~min}$ students must fulfill 20 tasks) that allow one to control 160 SEFI competencies from the zeroth to the second level in the areas of "Analysis and Calculus". Authors used Moodle system rather than Math-Bridge because it is more cross-platform and will help the project results to be more sustainable.

The main steps of the course modernization are: including new bridging section "Elementary Mathematics" at the beginning of Mathematical Analysis I; increasing the number of seminars and decreasing the number of lectures; increasing the number of consultations (from 15 to $30 \mathrm{~h}$ ); mandatory regular testing students during the term (includes using Math-Bridge) two tests per term; increasing the number of engineering examples in the course; using project learning (two projects per term at least). The topics of the projects are: "Approximate calculation of functions: a creation of the calculator for logarithms, trigonometric and hyperbolic functions", "Technical and physical applications of derivatives", "Research of the 
Table 7.33 Outlines of mathematical modeling courses at UNN and TUT

\begin{tabular}{l|l|l}
\hline Course information & UNN & TUT \\
\hline Bachelor/master level & Bachelor & Both \\
\hline Preferred year & 3 & $3-4$ \\
\hline Selective/mandatory & Selective & Selective \\
\hline Number of credits & 3 & 5 \\
\hline Teaching hours & 36 & 28 \\
\hline Preparatory hours & 54 & 80 \\
\hline Teaching assistants & - & - \\
\hline Computer labs & Available & Available \\
\hline Average number of students on the course & 10 & 60 \\
\hline Average pass \% & $100 \%$ & $95 \%$ \\
\hline$\%$ of international students & $0 \%$ & Less than 5\% \\
\hline & &
\end{tabular}

normal distribution, the logistic function, the chain line", "The calculation of the center of gravity", "Applications of Euler integral", and so on.

\subsubsection{Comparative Analysis of "Mathematical Modeling"}

The subject of study in this course are modeling methods and relevant mathematical model used in a variety of subject areas. As a result students should know methods of mathematical modeling. The course helps to learn how to model situations in order to solve problems. The course is based on the theory of differential equations and the theory of probability. There is a final test at the end of the semester. The "Mathematical Modeling" course at UNN is compared with the similar course "Basic Course on Mathematical Modeling" at Tampere University of Technology (TUT). Course outlines are given in Table 7.33.

The main goal of the course is in studying the fundamental methods of mathematical modeling. It contains such topics as the history of modeling, classes of models, differential equations and systems as mathematical models, dynamic systems, mathematical models in physics, chemistry, biology, ecology, models of a replication, the selection processes, continuous and discrete models of behaviour, models of adaptive behaviour, models of decision making, models of a selection of strategies, the selection and optimization, models of social and economic behaviour, optimal control, information models, the model of transmission and storage of information.

\subsubsection{Contents of the Course}

The comparison is based on the SEFI framework [1]. Prerequisite competencies are presented in Table 7.34. 
Table 7.34 Core 2 level prerequisite competencies of the mathematical modeling courses at UNN and TUT

\begin{tabular}{l|l|l}
\hline Core 2 & UNN & TUT \\
\hline Competency & $\mathrm{X}$ & $\mathrm{X}$ \\
\hline Ordinary differential equations & $\mathrm{X}$ & $\mathrm{X}$ \\
\hline The first-order differential equations & $\mathrm{X}$ & $\mathrm{X}$ \\
\hline The second-order differential equations & $\mathrm{X}$ & $\mathrm{X}$ \\
\hline Eigenvalue problems & $\mathrm{X}$ & $\mathrm{X}$ \\
\hline Nonlinear optimization & &
\end{tabular}

\subsubsection{Summary of the Results}

The main steps of the course modernization are decreasing the number of lectures (from $36 \mathrm{~h}$ to $18 \mathrm{~h}$ ), including independent work by students $(18 \mathrm{~h})$, mandatory regular testing of students (four times during the term, includes the use of MathBridge), using engineering examples in the course, using method of project learning (four projects per term). There are the following projects:

1. Introduction in mathematical modeling (simplest models: Volterra, Verhulst, Laurence, Lotka etc.). The aim of the project is to understand principles of mathematical modeling and the entity of the project's work.

2. Modeling eco-systems. The aim of the project is to apply qualitative research methods for mathematical models given in the form of systems of differential equations.

3. Chemical kinetics modeling. The aim of the project is to apply the Lyapunov function method.

4. The final project. The aim of the project is to apply information technologies in mathematical modeling. The topics of the projects are "The calculation of the index of competitiveness", "The calculation of evolutionary stable daily vertical migrations of aquatic organisms", "Models of strategies for socio-economic behaviour", "Neural network models", and so on.

\subsection{Analysis of Mathematical Courses in OMSU}

Sergey Fedosin

Ogarev Mordovia State University (OMSU), Department of Automated Systems of Information Management and Control, Saransk, Russia

Ivan Chuchaev

Ogarev Mordovia State University (OMSU), Faculty of Mathematics and IT, Saransk, Russia

e-mail: mathan@math.mrsu.ru

Aleksei Syromiasov

Ogarev Mordovia State University (OMSU), Department of Applied Mathematics, Differential Equations and Theoretical Mechanics, Saransk, Russia

e-mail: syal1@yandex.ru 


\subsubsection{Ogarev Mordovia State University (OMSU)}

Ogarev Mordovia State University (hereinafter OMSU) is a classical university, though a wide range of technical major programs are presented here. Since 2011 OMSU has the rank of National Research university, which reflects the university's high status in research in Russia. More than 24,000 students study in OMSU, almost 13,000 of them have intramural instruction.

There are several institutions in OMSU that may be referred to as STEM. They are: faculty of Architecture and Civil Engineering, faculty of Biotechnology and Biology, faculty of Mathematics and IT, institute of Mechanics and Energetics, institute of Physics and Chemistry, institute of Electronics and Lighting Technology and a branch in the town of Ruzaevka (institute of Machine-Building). In these institutions there are about 5000 students.

It is difficult to determine the number of STEM disciplines because every STEM major profile (or group of major profiles) has its special curriculum in mathematics, its special curriculum in physics and so on. So there is variety of STEM disciplines with the same name but with different contents. Totally, there are more than 100 different STEM disciplines in OMSU.

OMSU is the oldest and the biggest higher education institution in the Mordovian Republic. Its main campus is situated in Saransk, which is the capital of Mordovia. The institution was founded at the 1st of October, 1931 as Mordovian Agropedagogical Institute. Next year it was transformed into Mordovian Pedagogical Institute. Based on this institute Mordovian State University was organized in 1957. Finally, in 1970 it was named after the poet N.P. Ogarev.

More than 150,000 people graduated from the university during its history. OMSU graduates formed the backbone of scientific, engineering, pedagogical, medical and administrative staff in the Mordovian Republic. Many of the graduates work in other regions of Russia or abroad.

\subsubsection{Comparative Analysis of "Algebra and Geometry"}

Algebra and Geometry (AlGeo) for the major study programs Informatics and Computer Science (ICS) and Software Engineering (SE) is a fundamental mathematical course, so it is more of a theoretical than an applied course. OMSU tries to make it more applied by giving students programming tasks (for example, students must write a computer program which solves linear systems of equations using Gaussian elimination). Totally, there are about 50 first year students in two study programs (ICS and SE), and all of them must study this course.

The course information is to be compared with our European partner in the project Université Claude Bernard Lyon 1 (UCBL). The course outlines can be seen in Table7.35. 
Table 7.35 Outlines of algebra and geometry courses at OMSU and UCBL

\begin{tabular}{l|l|l}
\hline Course information & OMSU & UCBL \\
\hline Bachelor/master level & Bachelor & Bachelor \\
\hline Preferred year & 1 & 1 \\
\hline Selective/mandatory & Mandatory & Mandatory \\
\hline Number of credits & $6(216 \mathrm{~h})$ & $6+6$ \\
\hline Teaching hours & 108 & $60+60$ \\
\hline Preparatory hours & 108 & 120 \\
\hline Teaching assistants & No & yes \\
\hline Computer labs & $\begin{array}{l}\text { Several programming tasks as } \\
\text { homework }\end{array}$ & $\begin{array}{l}\text { Gaussian elimination using } \\
\text { Sage-math }\end{array}$ \\
\hline $\begin{array}{l}\text { Average number of students } \\
\text { on the course }\end{array}$ & 50 & 189 \\
\hline Average pass $\%$ & $85-90 \%$ & $65 \%$ \\
\hline$\%$ of international students & Less than $10 \%$ & $14 \%$ \\
\hline
\end{tabular}

A prerequisite for Algebra and Geometry is mathematics as studied at secondary school. Follow-up courses are Calculus, Discrete Mathematics, Probability theory and Statistics. The course of Algebra and Geometry is included in the group of mandatory mathematical courses that all the students in the ICS and IT-study programs must study during the first years.

Though course contents for ICS and SE study programs are almost the same, there are two departments responsible for the course of Algebra and Geometry. The Department of Calculus is responsible for this course for ICS profile. There are two full professors and ten associate professors working in this department. The Department of Applied Mathematics, Differential Equations and Theoretical Mechanics is responsible for this course for SE-study program. Four full professors, 14 associate professors and 3 teachers work in this department.

The overall number of credits for the course is 6 . Russian credit is $36 \mathrm{~h}$, so the total amount is $216 \mathrm{~h}$ for this course. Among them one has $36 \mathrm{~h}$ of lectures, $72 \mathrm{~h}$ of tutorials and $108 \mathrm{~h}$ of homework.

There is one 2-h lecture on Algebra and Geometry and two 2-h tutorials every week. During the tutorials students solve some problems (fulfill computational tasks) under the teacher's direction and control. Students may be given home tasks, which must be done during preparatory hours. We do not need computer labs for every tutorial, but some home tasks for this course are programming tasks. Students write simple programs on topics of the course, for example, they must write a program that solves a linear equation system. The programming language is of the student's choice. Totally, there are about 25 ICS students and about 25 SE students attending the course; for these profiles, lectures and tutorials are set separately. It is hard to mention the number of students who finish this certain course, because student expulsion in OMSU is the result of failing of two or more courses. But about $10-15 \%$ students of SE and ICS profiles usually drop out after the first 1 or 2 years of study, and as a rule, these students have problems in mathematics. Usually 
only Russian students study on ICS and SE programs; in OMSU most popular for international students is the Medical Institute.

The average age of students attending the course is 18 , and about $75 \%$ of the students are male. In OMSU there is no mandatory formal procedure of course rating; unofficial feedback contains more likes than dislikes of Algebra and Geometry.

The course of Algebra and Geometry is established for the first year students and is quite theoretical. So the pedagogy is traditional: students listen to lectures, fulfill some tasks during tutorials and do their homework. We think that younger students must have less educational freedom than older ones, and the role of the teacher in the learning process for younger students must be more explicit. That is why we do not use project-based learning in this course. But, of course, we try to make the learning process more interesting, sometimes funny and even competitive. For example, from time to time a group of students in the tutorial is divided into several subgroups and every subgroup fulfills some task. Solving linear equations systems by Cramer's rule is a good example of a task that can be "parallelized" so that every student in the subgroup does his/her part of the total work, and students in a subgroup collaborate. This kind of work in subgroups is very competitive and students like it. Blended learning is used episodically: some teachers use Moodle for distance learning. But for the students who have resident instruction (and here we discuss these students) it is more the exception than the rule.

A rating system is used for assessment at OMSU. The maximum rating is 100 points; one can get 70 points during the semester and only 30 points (as a maximum) is left for the exam procedure. In a semester students get their points for work in the classes and for fulfilling two-three large tests. These tests include a large amount of tasks; not only the answers, but the solutions are controlled by the teacher. An exam is passed in oral form and it includes two theoretical questions (like a theorem with a proof) and a computational task. A student's final rating sums up the semester and exam ratings. If this sum is 86 or more, the student's knowledge of the course is graded as excellent (ECTS grade A or B); if the sum is between 71 and 85, student has grade "good" (approximately ECTS grade C or D); if the sum is between 51 and 70, student's grade is "satisfactory" (ECTS grade E). Finally, a student fails (gets grade "non-satisfactory" which is equivalent to ECTS grade F) if his/her rating is 50 or less.

As for technology, high-level programming languages (C++ or Pascal) are used for homework. Programming (topics are harmonized with the course contents) is a mandatory part of the tests fulfilled by the students during the semester. This programming activity has an influence on the student's final rating.

Until 2014, TEL systems were not used in teaching of the course for students with resident instruction, but after participating in MetaMath project we plan to use Math-Bridge, GeoGebra and, perhaps, Moodle in teaching Algebra and Geometry. Now Moodle is used by students who study distantly (such distant learning is not the part of resident instruction now and is not included in this analysis).

E-mail and social networks are used sometimes to have a closer connection with students, to provide tasks for them and so on. 


\subsubsection{Contents of the Course}

The comparison is based on the SEFI framework [1], for each level from Core 0 to Core level 3 only subareas of mathematics are listed. The symbol " $X$ " means that all the competencies from this subarea are prerequisite for the course; exclusions are listed in explicit form. If few competencies (minor part) from the subarea are prerequisite, the description begins with "Only....".

Core 1 and Core 1 level prerequisite competencies are presented in Tables 7.36 and 7.37. Outcome competencies of level zero, one, two and three, are given in Tables 7.38, 7.39, 7.40, and 7.41.

Table 7.36 Core 0 level prerequisite competencies of algebra and geometry courses at OMSU and UCBL

\begin{tabular}{l|l|l}
\hline Core 0 & OMSU & UCBL \\
\hline Competency & $\mathrm{X}$ & $\mathrm{X}$ \\
\hline Arithmetic of real numbers & $\mathrm{X}$ & $\mathrm{X}$ \\
\hline Algebraic expressions and formulas & With some exceptions ${ }^{\mathrm{a}}$ & $\mathrm{X}$ \\
\hline Linear laws & $\mathrm{X}$ & $\mathrm{X}$ \\
\hline Quadratics, cubics and polynomials & $\mathrm{X}$ & $\mathrm{X}$ \\
\hline Proof & $\mathrm{X}$ & $\mathrm{X}$ \\
\hline Geometry & $\mathrm{X}$ & $\mathrm{X}$ \\
\hline Trigonometry & Only & $\mathrm{X}$ \\
\hline Coordinate geometry & $\mathrm{X}$ & $\mathrm{X}$ \\
\hline Trigonometric functions and applications & $\mathrm{X}$ & $\mathrm{X}$ \\
\hline Trigonometric identities & & $\mathrm{a}$ \\
\hline
\end{tabular}

${ }^{a}$ Obtain and use the equation of a line with known gradient through a given point; obtain and use the equation of a line through two given points; use the intercept form of the equation of a straight line; use the general equation $a x+b y+c=0$; determine algebraically whether two points lie on the same side of a straight line; recognize when two lines are perpendicular; interpret simultaneous linear inequalities in terms of regions in the plane

${ }^{\mathrm{b}}$ Calculate the distance between two points; give simple example of a locus; recognize and interpret the equation of a circle in standard form and state its radius and center; convert the general equation of a circle to standard form

Table 7.37 Core 1 level prerequisite competencies of algebra and geometry courses at OMSU and UCBL

\begin{tabular}{l|l|l}
\hline Core level 1 & OMSU & $\mathrm{UCBL}$ \\
\hline Competency & $\begin{array}{l}\text { Excluding: determine the unit vector in a specified } \\
\text { direction }\end{array}$ & $\mathrm{X}$ \\
\hline Vector arithmetic & $\begin{array}{l}\text { Excluding: all competencies due to vector product } \\
\text { and scalar triple product }\end{array}$ & $\mathrm{X}$ \\
\hline Vector algebra and applications
\end{tabular}


Table 7.38 Core 0 level outcome competencies of algebra and geometry courses at OMSU and UCBL

\begin{tabular}{l|l|l}
\hline Core 0 & OMSU & UCBL \\
\hline Competency & Those not in prereq. & $\mathrm{X}$ \\
\hline Linear laws & Only & Only $^{\mathrm{a}}$ \\
\hline Functions and their inverses & $\begin{array}{l}\text { Only: obtain the equation of the tangent and } \\
\text { normal to the graph of a function }\end{array}$ & same \\
\hline Rates of change and differentiation & Those not in prereq. & $\mathrm{X}$ \\
\hline Coordinate geometry &
\end{tabular}

${ }^{a}$ Understand how a graphical translation can alter a functional description; understand how a reflection in either axis can alter a functional description; understand how a scaling transformation can alter a functional description

${ }^{\mathrm{b}}$ All competencies excluding the properties of $1 / x$ and the concept of limit (Calculus)

Table 7.39 Core 1 level outcome competencies of algebra and geometry courses at OMSU and UCBL

\begin{tabular}{l|l|l}
\hline Core 1 & OMSU & UCBL \\
\hline Competency & $\mathrm{X}$ & $\mathrm{X}$ \\
\hline Conic sections & $\mathrm{X}$ & $\mathrm{X}$ \\
\hline 3D coordinate geometry & $\begin{array}{l}\text { Only: determine the unit vector in a } \\
\text { specified direction }\end{array}$ & $\mathrm{X}$ \\
\hline Vector arithmetic & $\begin{array}{l}\text { Only: all competencies due to vector } \\
\text { product and scalar triple product }\end{array}$ & $\mathrm{X}$ \\
\hline Vector algebra and applications & $\begin{array}{l}\text { Excluding: use appropriate software to } \\
\text { determine inverse matrices }\end{array}$ & Sage-math used \\
\hline Matrices and determinants & $\mathrm{X}$ & $\mathrm{X}$ \\
\hline $\begin{array}{l}\text { Solution of simultaneous linear } \\
\text { equations }\end{array}$ & With some exceptions ${ }^{\mathrm{a}}$ & $\mathrm{X}$ \\
\hline $\begin{array}{l}\text { Linear spaces and } \\
\text { transformations }\end{array}$ &
\end{tabular}

${ }^{\text {a }}$ Define a subspace of a linear space and find a basis for it; understand the concept of norm; define a linear transformation between two spaces; define the image space and the null space for the transformation

\subsubsection{Summary of the Results}

The main findings that course comparison has shown are: More exact name for OMSU course of Algebra and Geometry should be "Linear Algebra and Analytic Geometry". The French course is much more fundamental and much more extensive. Though OMSU course of Algebra and Geometry is one of the most theoretical in Software Engineering and Informatics and Computer Science study programs, it is more adapted to the specificity of these programs. It is less fundamental than the French one and this is the price to pay for having numerous IT-courses in the curriculum. Though the UCBL course of Algebra and Geometry is in total much more extensive, the amount of students' learning load per semester is 
Table 7.40 Core 2 level outcome competencies of algebra and geometry courses at OMSU and UCBL

\begin{tabular}{|c|c|c|}
\hline \multicolumn{3}{|l|}{ Core 2} \\
\hline Competency & OMSU & UCBL \\
\hline Linear optimization & Only $^{\mathrm{a}}$ & Same \\
\hline Algorithms & $\begin{array}{l}\text { Only: understand when an algorithm } \\
\text { solves a problem; understand the 'big O' } \\
\text { notation for functions }\end{array}$ & \\
\hline Helix & $\begin{array}{l}\text { Only: recognize the parametric equation of } \\
\text { a helix }\end{array}$ & \\
\hline $\begin{array}{l}\text { Geometric spaces } \\
\text { and transformations }\end{array}$ & With some exceptions ${ }^{\mathrm{b}}$ & With some exceptions ${ }^{c}$ \\
\hline
\end{tabular}

${ }^{a}$ Recognize a linear programming problem in words and formulate it mathematically; represent the feasible region graphically; solve a maximization problem graphically by superimposing lines of equal profit

bUnderstand the term 'invariants' and 'invariant properties'; understand the group representation of geometric transformations; classify specific groups of geometric transformations with respect to invariants

${ }^{c}$ Apply the Euler transformation, cylindrical coordinates, group representation, classification of group representation

Table 7.41 Core 3 level outcome competencies of algebra and geometry courses at OMSU and $\mathrm{UCBL}$

\begin{tabular}{|c|c|c|}
\hline \multicolumn{3}{|l|}{ Core 3} \\
\hline Competency & OMSU & UCBL \\
\hline Geometric core of computer graphics & With some exceptions ${ }^{\mathrm{a}}$ & \\
\hline Matrix decomposition & $\begin{array}{l}\text { Strassen's algorithm for quick multiplying } \\
\text { of matrices }\end{array}$ & \\
\hline
\end{tabular}

${ }^{a}$ Write a computer program that plots a curve which is described by explicit or parametric equations in cartesian or polar coordinates; know Bresenham's algorithm and Xiaolin Wu's algorithm of drawing lines on the display monitor

bigger in OMSU's course (108 vs. 60 teaching hours, that is, $80 \%$ more). In OMSU the percent of teaching hours is more than in UCBL (50\% vs. $36 \%$ ).

The conclusions of these findings are the measures for modernization of the course: Compared to UCBL, there is a lack of time in OMSU (on the programs that are involved in the MetaMath project) to study all algebra and geometry. So it is important to define learning goals and problems of the course more precisely and to follow them more strictly. It is necessary to collect study material according to the learning goals and problems defined. Study material should be even more illustrative than today and closer to IT-specificity. One of the ways to do this is to increase the number of computer programming labs; another is to use some software packages like GeoGebra. Students' preparatory work should be organized in a more effective way. The use of learning management systems (LMS) like Moodle or Math-Bridge will be very helpful here. The advantage of Math-Bridge is that this LMS is specially oriented to support mathematical courses. 
Table 7.42 Outlines of discrete mathematics (DM) and algorithm mathematics (AM) courses at OMSU and TUT

\begin{tabular}{l|l|l}
\hline Course information & OMSU & TUT \\
\hline Bachelor/master level & Bachelor & Bachelor \\
\hline Preferred year & 1 or 2 & 2 \\
\hline Selective/mandatory & Mandatory & Mandatory \\
\hline Number of credits & $6(216 \mathrm{~h})$ & $4(105 \mathrm{~h})$ \\
\hline Teaching hours & 108 & 49 \\
\hline Preparatory hours & 108 & 65 \\
\hline Teaching assistants & No & Yes \\
\hline Computer labs & $\begin{array}{l}\text { Several programming tasks as } \\
\text { homework }\end{array}$ & Available \\
\hline $\begin{array}{l}\text { Average number of students on the } \\
\text { course }\end{array}$ & 50 & 150 \\
\hline Average pass \% & $85-90 \%$ & $90 \%$ \\
\hline$\%$ of international students & Less than 10\% & Less than 5\% \\
\hline
\end{tabular}

\subsubsection{Comparative Analysis of "Discrete Mathematics"}

Discrete mathematics (DM) for the study programs ICS and SE is a fundamental mathematical course, so it is more theoretical than applied. But it is obvious that among all the theoretical courses it is the most applied and closest to the future of IT-professions of the students. OMSU tries to make the course more applied by giving the programming tasks to the students (for example, students must write a computer program which returns a breadth-first search in a connected graph). There are about 25 first year students in the SE program and 25 second year students in the ICS program, and all of them must study this course.

The corresponding course with our European partner Tampere University of Technology (TUT) is "Algorithm Mathematics" (AM). Course outlines can be seen in Table 7.42.

Prerequisite courses for Discrete Mathematics are secondary school mathematics and Algebra and Geometry. Follow-up courses are Mathematical Logic and Algorithm Theory, Theory of Automata and Formal Languages, Probability Theory and Statistics. The course of Discrete Mathematics is included in the group of mandatory mathematical courses that must be studied by all students of ICS and IT programs during the first years of study.

The Department of Applied Mathematics, Differential Equations and Theoretical Mechanics is responsible for this course for both programs, SE and ICS. Four full professors, 14 associate professors and 3 teachers work in this department. 
The overall number of credits is 6 . As mentioned before, in Russia we have $36 \mathrm{~h}$ in 1 credit, so the total amount is $216 \mathrm{~h}$ for this course. Among them are $36 \mathrm{~h}$ of lectures, $72 \mathrm{~h}$ of tutorials and $108 \mathrm{~h}$ of homework. Finnish credits contain less hours.

As for Algebra and Geometry, there is one 2-h lecture on Discrete Mathematics and two 2-h tutorials every week. During tutorials students solve some problems (fulfill computational tasks) under a teacher's direction. Students are given home tasks which must be done during preparatory hours. Computers are used also in controlling and grading the students' programming homework.

Course statistics for Discrete Mathematics is similar to that of Algebra and Geometry. There are about 25 ICS students and about 25 SE students attending the course; for these programs, lectures and tutorials on Discrete Mathematics are set separately. As said before, the number of students who do not finish the course is hard to give; after failing for the first time the student has two extra tries to pass the exam. Usually only Russian students study on ICS and SE programs. The average age of students attending the course is 19 (because for ICS students the course is in the second year of their study), and about $75 \%$ of the students are male. In OMSU there is no mandatory formal procedure of course rating; but as a rule students of ITprograms like the course because it is very "algorithmic" and close to programming.

The course of Discrete Mathematics is established for the first year or for second year students and is more theoretical than applied. The pedagogical methods used for this course are the same as for the course of Algebra and Geometry-and they are traditional. Students attend to lectures, fulfill tasks during tutorials and do their homework. Project work is not used widely, though some students interested in the course may be given additional large tasks (doing these tasks influences their rating). Similar to Algebra and Geometry, we do our best to make the learning process more interesting. For example, from time to time a group of students in the tutorial is divided into several subgroups and every subgroup fulfills some task. Searching a path in a connected graph by various methods is an example of such work. As mentioned before, this kind of work in subgroups is very competitive: students in different subgroups try to fulfill their task more quickly and more correctly than other subgroups. Blended learning is used episodically: some teachers use Moodle for distance learning. But for the students that have resident instruction (and here we discuss these students) it is more the exception than the rule.

Assessment and grading is similar to the course on "Algebra and Geometry", described above, and it is not repeated here.

\subsubsection{Contents of the Course}

The comparison is based on the SEFI framework [1]. Prerequisite competencies are presented in Table 7.43. Outcome competencies are given in Tables 7.44 and 7.45, 7.46, and 7.47.There are actually no other prerequisite competencies for Discrete Mathematics in OMSU. The course is taught from the very beginning of the field. 
Table 7.43 Prerequisite competencies of discrete mathematics and algorithm mathematics courses at OMSU and TUT

Core 1

\begin{tabular}{l|l|l}
\hline Competency & OMSU & TUT \\
\hline Proof & $\mathrm{X}$ & $\mathrm{X}$ \\
\hline
\end{tabular}

Table 7.44 Core 0 level outcome competencies of discrete mathematics and algorithm mathematics courses at OMSU and TUT

Core 0

\begin{tabular}{l|l|l}
\hline Competency & OMSU & TUT \\
\hline Sets & X & X \\
\hline
\end{tabular}

Table 7.45 Core 1 level outcome competencies of discrete mathematics and algorithm mathematics courses at OMSU and TUT

\begin{tabular}{l|l|l}
\hline Core 1 & OMSU & TUT \\
\hline Competency & With some exceptions ${ }^{\mathrm{a}}$ & $\mathrm{X}$ \\
\hline Sets & $\mathrm{X}$ & $\mathrm{X}$ \\
\hline Mathematical induction and recursion & $\mathrm{X}$ & \\
\hline Graphs & $\mathrm{X}$ & \\
\hline Combinatorics & & \\
\hline
\end{tabular}

${ }^{a}$ Compare the algebra of switching circuits to that of set algebra and logical connectives; analyze simple logic circuits comprising AND, OR, NAND, NOR and EXCLUSIVE OR gates

Table 7.46 Core 2 level outcome competencies of discrete mathematics and algorithm mathematics courses at OMSU and TUT

\begin{tabular}{l|l|l}
\hline Core 2 & OMSU & TUT \\
\hline Competency & $\begin{array}{l}\text { Only: use Euclid's algorithm for finding the } \\
\text { greatest common divisor. }\end{array}$ & \\
\hline Number systems & $\mathrm{X}$ & $\mathrm{X}$ \\
\hline Algebraic operations & $\begin{array}{l}\text { Only: define a sequence by a recursive } \\
\text { formula. }\end{array}$ & $\mathrm{X}$ \\
\hline Recursion and difference equations & $\mathrm{X}$ & $\mathrm{X}$ \\
\hline Relations & $\mathrm{X}$ & $\mathrm{X}$ \\
\hline Graphs & $\begin{array}{l}\text { Excluding: competencies due to NP and } \\
\text { NP-complete problems. }\end{array}$ & $\begin{array}{l}\text { Only: understand the group representation } \\
\text { of geometric transformations. }\end{array}$ \\
\hline Algorithms & &
\end{tabular}

\subsubsection{Summary of the Results}

The main findings that are consequent from the comparison made are as follows: According to the amount of learning hours and to the list of topics covered the OMSU course of Discrete Mathematics is more extensive than the course in TUT. 
Table 7.47 Core 3 level outcome competencies of discrete mathematics and algorithm mathematics courses at OMSU and TUT

\begin{tabular}{l|l|l}
\hline Core 3 & OMSU & TUT \\
\hline Competency & $\begin{array}{l}\text { Understanding the link between n-ary relations and relational } \\
\text { databases. Ability to normalize database and to convert from } \\
\text { 1NF to 2NF. }\end{array}$ & \\
\hline Combinatorics & $\begin{array}{l}\text { Write a computer program that finds the components of } \\
\text { connectivity, minimal spanning tree and so on. }\end{array}$ & $\begin{array}{l}\text { Using Shannon-Fano's and Huffman's methods to obtain } \\
\text { optimal code; the LZW zipping algorithm, the Diffie-Hellman } \\
\text { key exchange method; finding the RSA algorithm. }\end{array}$ \\
\hline Algebraic structures & \\
\hline
\end{tabular}

Many topics that are covered in OMSU are not covered in TUT. Teachers pay attention to algebra within the course of Discrete Mathematics both in OMSU and in TUT. So it is a good practice for IT-students to learn about algebraic structures in the framework of Discrete Mathematics. Finnish colleagues widely use e-learning (Moodle), which helps to organize students' preparatory work more effectively. This experience is very useful. Another useful experience is that Moodle helps teachers to collect feedback from students after finishing the course.

These findings motivate the following modernization measures: In general, OMSU course of Discrete Mathematics is rather good and meets the requirements for teaching IT-students. But it will be useful to make it some more illustrative. It will be a good practice to continue using computer programming home works. In OMSU we should use e-learning to organize preparatory work for students in a more effective way. Math-Bridge and Moodle will help here. Also it will be suitable to collect some feedback from students.

\subsection{Analysis of Mathematical Courses in TSU}

Ilia Soldatenko and Alexander Yazenin

Tver State University (TSU), Information Technologies Department, Applied Mathematics and Cybernetics Faculty, Tver, Russia

e-mail: soldis@tversu.ru; Yazenin.AV@tversu.ru

Irina Zakharova

Tver State University (TSU), Mathematical Statistics and System Analysis Department, Applied Mathematics and Cybernetics Faculty, Tver, Russia

e-mail: zakhar_iv@mail.ru

Dmitriy Nikolaev

Tver State University (TSU), International Relations Center, Tver, Russia

e-mail: Nikolaev.DS@tversu.ru 


\subsubsection{Tver State University (TSU)}

Tver State University is one of the largest scientific and educational centers in Central Russia. Responding actively to modern-day challenges, the institution of higher education is developing dynamically, while preserving tradition. TSU ensures the preparation of qualified specialists in the sphere of physico-mathematical, natural, human and social sciences, as well as of education and pedagogy, economy and administration among other areas. Tver State University is a classical institution with a total quantity of students equal to about 10 thousand, about half of which pursue STEM courses.

The Tver State University has had a long and difficult developmental path. The university's history starts on December 1, 1870, when, in Tver, a private pedagogical school named after P.P. Maximovich was opened. It was later on reformed in 1917 to become the Tver Teachers' Institute, after which it became the Kalinin Pedagogical Institute. Before the 1970s, tens of thousands of specialists graduated at the Pedagogical Institute with university qualifications. On September 1, 1971, an outstanding event took place in the Institute's history; it was renamed Kalinin State University.

In 1990, the Kalinin State University was renamed Tver State University. Its graduates work successfully at schools, scientific institutions, as well as in economic and social organizations. The university's scholars have also made a considerable contribution to making up and developing many scientific fields and research areas. Today, our personnel consists of about 600 professors, including 100 doctors, full professors and about 400 professors holding a $\mathrm{PhD}$ degree, as well as associate professors.

TSU is comprised of 12 faculties and 2 institutes, which are the following:

- Institute of Pedagogical Education and Social Technologies,

- Institute of Economics and Management,

- Faculty of Biology,

- Faculty of History,

- Faculty of Mathematics,

- Faculty of Geography and Geo-ecology,

- Faculty of Foreign Languages and International Communication,

- Faculty of Applied Mathematics and Cybernetics,

- Faculty of Psychology,

- Faculty of Sport,

- Physico-Technical Faculty,

- Faculty of Philology,

- Faculty of Chemistry and Technology,

- Faculty of Law.

Our personnel consists of about 600 professors, including 100 doctors, full professors and about 400 professors holding a $\mathrm{PhD}$ degree, as well as associate professors. 
The main directions of research and development at the University are carried out in the field of natural and exact sciences: mathematics, mechanics, physics, chemistry, biology, geo-ecology and computer science. There is also a lot of research in the fields of the humanities and social sciences, such as sociology, linguistics, literature, history, economics, state and law, as well as in protection of the environment, human ecology and demography. At the University, there are over 20 scientific schools carrying out research in relevant scientific topics of natural sciences and humanities within 15 fields of study. Their activities are recognized internationally, as well as domestically.

TSU maintains close ties with more than 30 universities in Europe, the USA and the Commonwealth of Independent States, and it carries out exchange programs, and it provides education to international students and actively participates in various international educational programs. Tver State University's long-standing partners include the University of Osnabruck and the University of Freiburg (Germany), the University of Montpellier and the University of Clermont-Ferrand (France), the University of Turku and the University of Joensuu (Finland), the University of Ghent (Belgium), the University of Xiamen (China), St. Cyril and St. Methodius University of Veliko Tarnovo (Bulgaria), the University of Glasgow (UK), etc. Thanks to many years of international cooperation, Tver State University has established educational and cultural ties with these institutions and has increased exchanges in the field of scientific research. TSU is one of the few higher education institutions that develops international academic mobility.

Annually, about 100 students from TSU's different departments attend a course of study for one semester at universities in the Federal Republic of Germany, France, Finland, Bulgaria, Poland, and the USA. Students attend classes according to the profile of their learning, and they take exams. Students perfect their knowledge of foreign languages, acquire the invaluable experience of studying at a higher learning institution abroad, and make new and interesting friends.

The number of TSU students studying for a semester at the University of Osnabruck at their own expense keeps increasing each year. The university's involvement in the "East-West" research faculty exchange program jointly financed by DAAD and the University of Osnabruck has facilitated the creation of close-knit research teams in the field of mathematics, geography, chemistry, botany and the publishing of books, articles and other publications.

Since 2000, students coming from different universities in Finland have taken part in inclusive semester courses at the Department of Russian as a Foreign Language. The project is financed by the Ministry of Education of Finland. Since 2005 TSU has been a participant of "FIRST" program (Russia-Finland Student Exchange Program). A similar program has been conducted with UK universities and the cooperation of the RLUS Company.

The process of TSU integration into the global educational space is also realized through the involvement in different international educational schemes. Each year, more than 200 students and post-graduate students from foreign universities (including the CIS and the Baltic nations) take a course at Tver State University. 
In recent years the university has significantly expanded its cooperation with the Oxford-Russia Fund. This project is supervised by the TSU Inter-University Centre for International Cooperation. Annually 120 TSU students are awarded scholarships by the Fund. The University was also given access to the electronic library of the University of Oxford. TSU was among the first 10 partners of the Foundation to gain access to online versions of 500 British titles. The project also envisages the TSU Library receiving books on art, languages, history, etc.

The cooperation with the Fulbright Foundation allows TSU to annually host US guest speakers delivering lectures on international affairs, global terrorism, etc. TSU faculty and students are actively involved in different educational and research programs and projects financed by the European Union, the Ford Foundation, CIMO, the DAAD, the IREX, etc.

\subsubsection{Mathematics Education in Tver State University}

The Faculty of Applied Mathematics and Cybernetics (AM\&C) and the Mathematical Faculty are responsible for conducting mathematical courses at the university. The Mathematical Faculty focuses on pedagogical programs; AM\&C on applied mathematics. The Faculty of Applied Mathematics and Cybernetics was founded in 1977, though the specialization "Applied Mathematics" was opened in 1974. It is in many areas the leading educational department in the University. It includes more than 32 full-time teachers, including 19 candidates and 10 doctors of sciences who have major scientific achievements in their respective fields of expertise. Teaching staff also consist of representatives of employers, who have extensive practical experience.

Currently the Faculty has four educational programs:

- Applied Mathematics and Computer Science,

- Fundamental Computer Science and Information Technologies,

- Computer Science in Business,

- Applied Computer Science.

In addition to these programs, the Faculty provides training in mathematics and appropriate applied disciplines in other faculties. The Faculty has four departments:

1. Information Technologies department (fields of expertise: intellectual information systems, fuzzy systems and soft computing technologies; theory of possibilities; probabilistic and probabilistic optimization and decision-making; portfolio theory under conditions of hybrid uncertainty; processing and recognition of signals and images; multimedia technologies).

2. Computer Science department (fields of expertise: theoretical programming, theory of finite models, theory of multi-agent systems, theoretical linguistics, the development of expert systems; databases). 
3. Mathematical Statistics and System Analysis department (fields of expertise: theory of sustainable and natural exponential probability distributions of data; application of probabilistic and statistical methods in econometrics, financial and actuarial mathematics, analysis of telecommunication networks; choice theory, multicriteria decision making under uncertainty).

4. Mathematical Modeling and Computational Mathematics department (fields of expertise: theoretical basis of mathematical modeling of complex systems; development of mathematical models of critical states of nonlinear dynamical systems, assessment of the safety performance of these systems; mathematical models and methods for the identification of objects with large interference and decision making under uncertainty, analysis and solution finding using mathematical modeling applications: solution of problems of nonlinear elastic and viscoelastic materials; solving problems of geophysical hydrodynamics and hydrothermodynamics; solving problems of heat conduction; analysis of the structures of insurance funds, development of recommendations on the organization of insurance funds; development and application of optimization methods for solving economic problems; development and implementation of a measurement system of numerical methods for optimal digital video and audio signals).

The faculty also has three scientific schools: Fuzzy systems and soft computing, Mathematical modeling, Theoretical foundations of computer science.

\subsubsection{Comparative Analysis of "Probability Theory and Mathematical Statistics"}

"Probability Theory and Mathematical Statistics" is a mandatory course at Tver State University; it combines theoretical and applied approaches. Mathematics plays a key role in the course, and it in its turn forms a foundation for several other applied special disciplines in corresponding educational programs. The course was compared with two courses at Tampere University of Technology (TUT): "Probability Calculus" and "Statistics". The course outlines can be seen in Table 7.48.

Prerequisite courses at TSU are Linear Algebra, Calculus and Differential Equations, and follow-up courses are Possibility Theory and Fuzzy Logic, Econometrics, Theory of Stochastic Processes and Methods of Socio-Economic Forecasting. At TUT, prerequisite courses are Engineering Mathematics 1-4, and follow-up courses are all the other courses provided by the department. In Tver State University this course is included in the group of core mandatory mathematical courses of the corresponding study programs and is taught by the Applied Mathematics and Cybernetics department. In TUT the course is taught by Department of Mathematics and it is also included in the group of mandatory mathematical courses.

The teaching of the course at TSU is more theory-based and unfortunately does not include any innovative pedagogical methods and tools, such as blended learning, 
Table 7.48 Outlines of the courses on probability theory and mathematical statistics at TSU and TUT

\begin{tabular}{l|l|l}
\hline Course information & TSU & TUT \\
\hline Bachelor/master level & Bachelor & Bachelor \\
\hline Preferred year & $2-3$ & 2 \\
\hline Selective/mandatory & Mandatory & Both \\
\hline Number of credits & 10 & $4+4$ \\
\hline Teaching hours & 148 & $42+42$ \\
\hline Preparatory hours & 220 & 132 \\
\hline Teaching assistants & $0-1$ & $1-4$ \\
\hline Computer labs & $\begin{array}{l}\text { Practice with MATLAB, } \\
\text { Excel, C++ }\end{array}$ & Practice in R-software \\
\hline $\begin{array}{l}\text { Average number of students on the } \\
\text { course }\end{array}$ & 85 & 200 \\
\hline Average pass \% & $90 \%$ & $90 \%$ \\
\hline$\%$ of international students & $10 \%$ & $<5 \%$ \\
\hline
\end{tabular}

flipped classroom, MOOCs, project-based learning, inquiry-based learning, collaborative learning, gamification. In TUT on the other hand one can find blended learning, collaborative learning, project-based approach and active use of modern TEL tools for administration, teaching and assessment purposes. Not all modern pedagogical technologies are used in TUT but those that do exist in educational process are applied widely and successfully.

Assessment, testing and grade computation do not differ from what is described in Chap. 3. At TSU, as in all Russian universities, a general rating system is implemented. Rating is the sum of points for all courses taken during the whole of 4 years of education. The rating comes into play when it is time for a student to choose his/her major (graduating chair), which has influences on the further curriculum (set of special professional courses) and Bachelor thesis topics. The exam for the course is verbal; during the semester lecturer performs several written tests. A student can receive 100 points for the discipline, 60 of which come from activities during semester and 40 from exam work. The semester is also divided into two modules, each of which gives a maximum of 30 points. The grading systems is the following: less than 50 points is unsatisfactory (grade "2"), from 50 to 69 points satisfactory (grade "3"), from 70 to 84 good (grade "4"), more than 84 excellent (grade "5").

TUT on the other hand does not have a general rating system and uses six grades according to European ECTS scale to assess results of education in each course: excellent (grade A) 5 points; very good (grade B) 4 points; good (grade C) 3 points; very satisfactory (grade D) 2 points; satisfactory (grade E) 1 point; unsatisfactory (grade F) 0 points.

As regards educational software and TEL systems in TSU in the course: MATLAB and Excel are used in tutorials. Lecturers teach students how to use the tools, but these are not mandatory for solving practical and assessment tasks. A student may also choose to write a program in any high-level multi-purpose 
language, which he or she knows already. In TUT, educational software and TEL systems are used in the following ways: Moodle for file sharing and course information, POP for course and exam enrollment and course grades, and R is used as support for exercises. Furthermore, students in TUT form their individual learning paths from the very beginning of their studies with the help of specialized software. There is an electronic catalog of courses from which a student should choose an appropriate number of courses with the needed amount of credits. This is significantly different from what we have in Tver State University as well as in all other Russian universities.

\subsubsection{Contents of the Course}

The comparison is based on the SEFI framework [1]. Prerequisite competencies are presented in Table 7.49. Outcome competencies are given in Tables 7.50, 7.51, and 7.52.

\subsubsection{Summary of the Results}

Comparative analysis of the disciplines shows that thematic contents and learning outcomes are almost identical. The difference is observed in the number of hours. One should also note the active use of information technologies and, in particular, elearning systems in TUT. This allows this university to take out some of the material

Table 7.49 Prerequisite competencies of the probability theory and mathematical statistics courses at TSU and TUT

\begin{tabular}{l|l|l}
\hline Core 1 & TSU & TUT \\
\hline Competency & $\begin{array}{l}\text { Excluding: calculate the mode, } \\
\text { median and mean for a set of } \\
\text { data items }\end{array}$ & \\
\hline Data handling & X & X \\
\hline Arithmetic of real numbers & X & X \\
\hline Algebraic expressions and formulas & X & X \\
\hline Functions and their inverse & $\mathrm{X}$ & $\mathrm{X}$ \\
\hline $\begin{array}{l}\text { Sequences, series, binomial } \\
\text { expansions }\end{array}$ & $\mathrm{X}$ & $\mathrm{X}$ \\
\hline $\begin{array}{l}\text { Logarithmic and exponential } \\
\text { functions }\end{array}$ & $\mathrm{X}$ & $\mathrm{X}$ \\
\hline Indefinite integration & With some exceptions ${ }^{\mathrm{a}}$ & With some exceptions \\
\hline $\begin{array}{l}\text { Definite integration, applications to } \\
\text { areas and volumes }\end{array}$ & $\mathrm{X}$ & $\mathrm{X}$ \\
\hline Sets & & \\
\hline
\end{tabular}

${ }^{\text {a}}$ Use trapezoidal and Simpson's rule for approximating the value of a definite integral 
Table 7.50 Core 0 level outcome competencies of the probability theory and mathematical statistics courses at TSU and TUT

Core 0

Competency

Calculate the mode, median and mean for a set of data items

Define the terms 'outcome', 'event' and 'probability'

Calculate the probability of an event by counting outcomes

Calculate the probability of the complement of an event

Calculate the probability of the union of two mutually exclusive events

Calculate the probability of the union of two events

Calculate the probability of the intersection of two independent events

Table 7.51 Core 1 level outcome competencies of the probability theory and mathematical statistics courses at TSU and TUT

\begin{tabular}{|c|c|c|}
\hline \multicolumn{3}{|l|}{ Core 1} \\
\hline Competency & TSU & TUT \\
\hline $\begin{array}{l}\text { Calculate the range, inter-quartile range, variance and standard deviation for a set } \\
\text { of data items }\end{array}$ & $\mathrm{X}$ & $\mathrm{X}$ \\
\hline Distinguish between a population and a sample & $\mathrm{X}$ & $\mathrm{X}$ \\
\hline $\begin{array}{l}\text { Know the difference between the characteristic values (moments) of a population } \\
\text { and of a sample }\end{array}$ & $\mathrm{X}$ & $\mathrm{X}$ \\
\hline Construct a suitable frequency distribution from a data set & $\mathrm{X}$ & \\
\hline Calculate relative frequencies & $\mathrm{X}$ & \\
\hline Calculate measures of average and dispersion for a grouped set of data & $\mathrm{X}$ & \\
\hline Use the multiplication principle for combinations & $\mathrm{X}$ & $\mathrm{X}$ \\
\hline Interpret probability as a degree of belief & $\mathrm{X}$ & \\
\hline Understand the distinction between a priori and a posteriori probabilities & $\mathrm{X}$ & $\mathrm{X}$ \\
\hline Use a tree diagram to calculate probabilities & $\mathrm{X}$ & \\
\hline Know what conditional probability is and be able to use it (Bayes' theorem) & $\mathrm{X}$ & $\mathrm{X}$ \\
\hline Calculate probabilities for series and parallel connections & $\mathrm{X}$ & \\
\hline Define a random variable and a discrete probability distribution & $\mathrm{X}$ & $\mathrm{X}$ \\
\hline State the criteria for a binomial model and define its parameters & $\mathrm{X}$ & $\mathrm{X}$ \\
\hline Calculate probabilities for a binomial model & $\mathrm{X}$ & $\mathrm{X}$ \\
\hline State the criteria for a Poisson model and define its parameters & $\mathrm{X}$ & $\mathrm{X}$ \\
\hline Calculate probabilities for a Poisson model & $\mathrm{X}$ & $\mathrm{X}$ \\
\hline State the expected value and variance for each of these models & $\mathrm{X}$ & $\mathrm{X}$ \\
\hline Understand that a random variable is continuous & $\mathrm{X}$ & $\mathrm{X}$ \\
\hline $\begin{array}{l}\text { Explain the way in which probability calculations are carried out in the } \\
\text { continuous case }\end{array}$ & $\mathrm{X}$ & \\
\hline Relate the general normal distribution to the standardized normal distribution & $\mathrm{X}$ & $\mathrm{X}$ \\
\hline Define a random sample & $\mathrm{X}$ & $\mathrm{X}$ \\
\hline Know what a sampling distribution is & $\mathrm{X}$ & $\mathrm{X}$ \\
\hline Understand the term 'mean squared error' of an estimate & $\mathrm{X}$ & \\
\hline Understand the term 'unbiasedness' of an estimate & $\mathrm{X}$ & \\
\hline
\end{tabular}


Table 7.52 Core 2 level outcome competencies of the probability theory and mathematical statistics courses at TSU and TUT

\begin{tabular}{l|l|l}
\hline Core 2 & TSU & TUT \\
\hline Competency & $\mathrm{X}$ & $\mathrm{X}$ \\
\hline Compare empirical and theoretical distributions & $\mathrm{X}$ & \\
\hline Apply the exponential distribution to simple problems & $\mathrm{X}$ & $\mathrm{X}$ \\
\hline Apply the normal distribution to simple problems & $\mathrm{X}$ & $\mathrm{X}$ \\
\hline Apply the gamma distribution to simple problems & $\mathrm{X}$ & $\mathrm{X}$ \\
\hline Understand the concept of a joint distribution & $\mathrm{X}$ & $\mathrm{X}$ \\
\hline Understand the terms 'joint density function', 'marginal distribution functions' & $\mathrm{X}$ & $\mathrm{X}$ \\
\hline Define independence of two random variables & $\mathrm{X}$ & $\mathrm{X}$ \\
\hline Solve problems involving linear combinations of random variables & $\mathrm{X}$ & $\mathrm{X}$ \\
\hline Determine the covariance of two random variables & $\mathrm{X}$ & $\mathrm{X}$ \\
\hline Determine the correlation of two random variables & $\mathrm{X}$ & \\
\hline Realize what the normal distribution is not reliable when used with small samples & $\mathrm{X}$ & $\mathrm{X}$ \\
\hline Use tables of the $t$-distribution & $\mathrm{X}$ & $\mathrm{X}$ \\
\hline Use tables of the $F$-distribution & $\mathrm{X}$ & $\mathrm{X}$ \\
\hline Use the method of pairing where appropriate & $\mathrm{X}$ & $\mathrm{X}$ \\
\hline Use tables for chi-squared distributions & $\mathrm{X}$ & $\mathrm{X}$ \\
\hline Decide on the number of degrees of freedom appropriate to a particular problem & $\mathrm{X}$ & $\mathrm{X}$ \\
\hline Use the chi-square distribution in tests of independence (contingency tables) & $\mathrm{X}$ & \\
\hline Use the chi-square distribution in tests of goodness of fit & $\mathrm{X}$ & $\mathrm{X}$ \\
\hline Set up the information for a one-way analysis of variance & &
\end{tabular}

for independent study and focus on really difficult topics of the discipline. Elearning systems also allow one to automate and, as a result, simplify the knowledge assessment process. This automation seems to be important for TUT, whose class sizes substantially exceed the size of study groups in the TSU.

All this suggests the need for more active use of e-learning systems, as well as blended learning methodology in the educational process in Tver State University. It is also worth noting that in TUT part of the basic (input) material is moved to a bridging course "Mathematics Basic Skills Test \& Remedial Instruction". The material in this course is designed primarily for successful mastering of the engineering mathematics courses. Nevertheless, this experience should also be useful for Tver State University. In particular, a bridging course "Basics of Elementary Mathematics" should be created, which will include the material from the following topics of mathematics: Set theory, elementary functions and their graphs, series and their properties, elements of combinatorics, equations and inequalities. 
Table 7.53 Outline of possibility theory and fuzzy logic course at TSU

\begin{tabular}{l|l}
\hline Course information & TSU \\
\hline Bachelor/master level & Bachelor \\
\hline Preferred year & 3 \\
\hline Selective/mandatory & Selective \\
\hline Number of credits & 4 \\
\hline Teaching hours & 68 \\
\hline Preparatory hours & 76 \\
\hline Teaching assistants & $1-2$ \\
\hline Computer labs & Not used \\
\hline Average number of students on the course & 50 \\
\hline Average pass \% & $95 \%$ \\
\hline$\%$ of international students & $17 \%$ \\
\hline &
\end{tabular}

\subsubsection{Comparative Analysis of "Possibility Theory and Fuzzy Logic"}

Because of the fact that the discipline "Possibility Theory and Fuzzy Logic" is not widely spread among both domestic and foreign universities and is a particular feature of Tver State University, the comparative analysis was performed with the course "Probability Theory and Mathematical Statistics". However, because of the relative proximity of the disciplines all its conclusions including recommendations on the modernization of the course are applicable to "Possibility Theory and Fuzzy Logic", as well. Below is the profile of the second course in terms of its structure and prerequisite SEFI competencies. It is an elective course which combines both theoretical and applied approaches. Mathematics plays a key role in it. The course outline can be seen in Table 7.53.

Prerequisite courses are Probability Theory and Methods of Optimisation and Decision Making. There are no follow-up courses for "Possibility Theory and Fuzzy Logic", because this course is included in the elective part of the professional cycle of the corresponding educational programs. It is taught by lecturers from the Applied Mathematics and Cybernetics department. The teaching of this course is more theory-based and classical without wide support of e-learning tools and methods.

\subsubsection{Contents of the Course on Possibility Theory and Fuzzy Logic}

The comparison is based on the SEFI framework [1]. Prerequisite competencies are presented in Tables 7.54, 7.55, and 7.56. 
Table 7.54 Core 0 level prerequisite competencies of the course on possibility theory and fuzzy logic at TSU

\begin{tabular}{l|l}
\hline Core 0 & TSU \\
\hline Competency & $\mathrm{X}$ \\
\hline Arithmetic of real numbers & $\mathrm{X}$ \\
\hline Algebraic expressions and formulas & $\mathrm{X}$ \\
\hline Linear laws & $\mathrm{X}$ \\
\hline Functions and their inverses & $\mathrm{X}$ \\
\hline Logarithmic and exponential functions & $\mathrm{X}$ \\
\hline Indefinite integration & $\mathrm{X}$ \\
\hline Proof & $\mathrm{X}$ \\
\hline Sets & With some exceptions \\
\hline Coordinate geometry & $\mathrm{X}$ \\
\hline Probability & \\
\hline
\end{tabular}

${ }^{\text {a}}$ Find the angle between two straight lines, recognize and interpret the equation of a circle in standard form and state its radius and center, convert the general equation of a circle to standard form, derive the main properties of a circle, including the equation of the tangent at a point, recognize the parametric equations of a circle, use polar coordinates and convert to and from Cartesian coordinates

Table 7.55 Core 1 level prerequisite competencies of the course on possibility theory and fuzzy logic at TSU

\begin{tabular}{l|l}
\hline Core 1 & TSU \\
\hline Competency & With some exceptions \\
\hline Rational functions & $\mathrm{X}$ \\
\hline Functions & $\mathrm{X}$ \\
\hline Solution of simultaneous linear equations & $\mathrm{X}$ \\
\hline Simple probability & $\mathrm{X}$ \\
\hline Probability models & \\
\hline
\end{tabular}

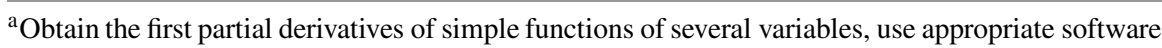
to produce $3 \mathrm{D}$ plots and/or contour maps

Table 7.56 Core 2 level prerequisite competencies of the course on possibility theory and fuzzy logic at TSU

\begin{tabular}{|c|c|}
\hline \multicolumn{2}{|l|}{ Core 2} \\
\hline Competency & TSU \\
\hline Linear optimization & With some exceptions ${ }^{a}$ \\
\hline $\begin{array}{l}\text { a Understand the mea } \\
\text { ables in reformulati } \\
\text { the concept of dualit } \\
\text { the dual to a given p }\end{array}$ & $\begin{array}{l}\text { ig and use of slack vari- } \\
\text { a problem, understand } \\
\text { nd be able to formulate } \\
\text { lem }\end{array}$ \\
\hline
\end{tabular}

Unfortunately SEFI Framework does not have learning outcomes suitable for "Possibility Theory and Fuzzy Logic". After successful completion of the course, a student should have to master:

- the mathematical apparatus of the possibility theory and knowledge representation in computer science, 
- skills to model uncertainty of probabilistic type in decision-making problems,

- methods of knowledge representation with elements of possibilistic uncertainty, they should be able to:

- use this mathematical apparatus in the development of fuzzy decision support systems,

- apply mathematical apparatus of possibility theory in modern information technologies,

- use soft computing technologies for solving applied problems,

they should know:

- elements of fuzzy sets theory, fuzzy logic theory and modern possibility theory, soft computing technologies,

- fundamental concepts and system methodologies in the field of information technologies based on soft computing,

- principles of construction of fuzzy decision support systems.

\subsubsection{Summary of the Results}

Because of the relative proximity of this discipline to Probability Theory all the conclusions for the latter discipline are applicable to "Possibility Theory and Fuzzy Logic" as well.

\section{Reference}

1. SEFI (2013), "A Framework for Mathematics Curricula in Engineering Education". (Eds.) Alpers, B., (Assoc. Eds) Demlova M., Fant C-H., Gustafsson T., Lawson D., Mustoe L., OlssonLehtonen B., Robinson C., Velichova D. (http://www.sefi.be).

Open Access This chapter is licensed under the terms of the Creative Commons Attribution 4.0 International License (http://creativecommons.org/licenses/by/4.0/), which permits use, sharing, adaptation, distribution and reproduction in any medium or format, as long as you give appropriate credit to the original author(s) and the source, provide a link to the Creative Commons license and indicate if changes were made.

The images or other third party material in this chapter are included in the chapter's Creative Commons license, unless indicated otherwise in a credit line to the material. If material is not included in the chapter's Creative Commons license and your intended use is not permitted by statutory regulation or exceeds the permitted use, you will need to obtain permission directly from the copyright holder.

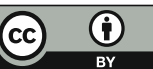

